D) Check for updates

Cite this: Mater. Horiz., 2020, 7, 2882

Received 30th March 2020 , Accepted 13th July 2020

DOI: $10.1039 / \mathrm{d} 0 \mathrm{mh} 00535 \mathrm{e}$

rsc.li/materials-horizons

\section{Evolution of self-healing elastomers, from extrinsic to combined intrinsic mechanisms: a review}

\author{
Saul Utrera-Barrios, (D) Raquel Verdejo, (D) Miguel A. López-Manchado (D) and \\ Marianella Hernández Santana (iD *
}

\begin{abstract}
The evolution of self-healing polymers has resulted in a myriad of healing designs that have given way to complex systems capable of supporting multiple cycles, among other features. This progression enables us to propose the implementation of a timeline that classifies self-healing polymers in generations based on the healing mechanism, and correlated with historical development. The first generation employed the encapsulation of external healing agents; the second one, based on intrinsic mechanisms, applied reversible chemistries; and the third generation was inspired by natural examples such as plants and human skin, in which the healing agent is embedded in vascular networks. Despite great efforts and, with a few exceptions, polymers with high healing efficiency and high mechanical performance are not common. To improve this situation, a combination of different mechanisms is currently emerging, giving birth to the fourth generation of self-healing materials. This article, focused on self-healing elastomers, provides a rigorous overview of this new generation, in which the combination of covalent bonds and non-covalent interactions provides an optimal balance between mechanical performance and repairability. The implementation of this concept leads to materials with real commercial potential in functional applications, such as coatings, sensors, actuators, controlled release of drugs, seals, gaskets, hoses, and even high-performance applications such as tires and railway components.
\end{abstract}

Institute of Polymer Science and Technology (ICTP-CSIC), Juan de la Cierva, 3, 28006, Madrid, Spain. E-mail: marherna@ictp.csic.es

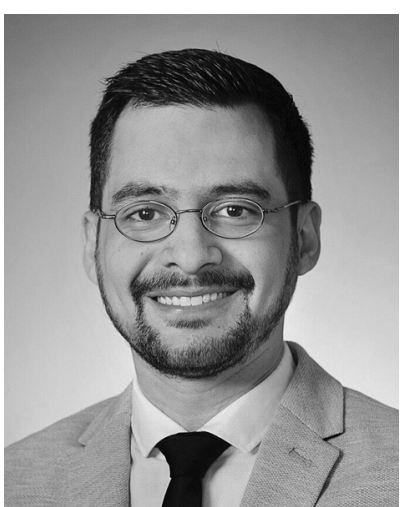

Saul Utrera-Barrios
Saul Utrera-Barrios (SUB) is a Materials Engineer (Simon Bolivar University, Venezuela) with a MSc in Plastics and Rubber (Menendez Pelayo International University UIMP - Spanish National Research Council CSIC, Spain) and a PhD candidate in Advanced Chemistry (Complutense University of Madrid, Spain). Since 2018, he has developed his experimental work at the Institute of Polymer Science and Technology (ICTPCSIC) in the area of elastomerbased composite materials with self-healing capability, under the supervision of Dr Marianella Hernández Santana and Prof. Miguel Ángel López Manchado. His scientific main interests include the development, characterization, and production of elastomer-based composite materials and intrinsic self-healing concepts.

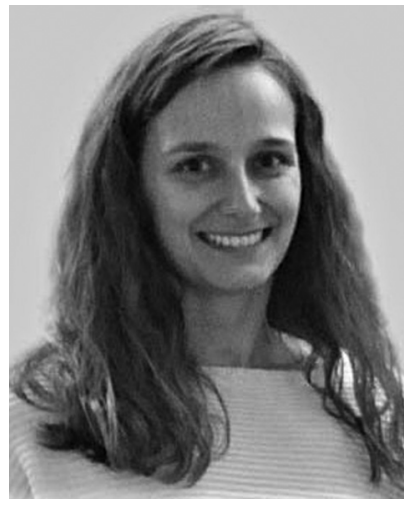

Raquel Verdejo
Raquel Verdejo (RV) is Senior Research Scientist at the Institute of Polymer Science and Technology (ICTP-CSIC). She did her PhD in Metallurgy and Materials at the University of Birmingham (UK) and later joined Imperial College London. She returned to Spain thanks to a Juan de la Cierva and afterwards held a prestigious Ramón y Cajal position, getting tenure in 2010. She is currently the Academic Director of the Master of High Specialization in Plastics and Rubber (UIMP-CSIC). Her main line of research is focused on the development of polymer composites and nanocomposites with special emphasis on polymer foams. 


\section{Introduction}

The history of humankind has been classified in periods according to the use given to materials to meet their basic needs. In all cases, the discovery of new materials and the advancement in the manipulation of those already known implied a real revolution in social structures. With the impressive development attained between the 20th and the 21st century, humanity began to require new materials with properties on demand. Among these properties, self-healing has arisen as an unstoppable development in the last 20 years.

Self-healing materials are attractive in the current environmental context, where there is a need for reducing waste and extending the lifetime of products. Besides, in the framework of the circular economy, ${ }^{1,2}$ certain polymers, such as elastomers or thermosets, are inappropriate because, despite great efforts, ${ }^{3,4}$ their reprocessing remains a challenge. Due to their importance in industrial applications, it has become mandatory to make them compatible with the circular economy model. Precisely, one possible path to achieve it is by conferring them with self-healing capability.

One can find in the literature some important reviews on the development of self-healing materials. ${ }^{5-7}$ However, there are just a few in the field of elastomers ${ }^{8-11}$ and to the best of our knowledge there is no specific one considering the combination of healing moieties, a new trend that has shown exponential growth in recent years. This review initially presents a brief overview of the evolution of self-healing, divided into generations, and later compiles the advances in the last five years in the field of self-healing rubbers. We define four generations and structure the review based on the nature of the involved bonds and interactions: non-covalent, covalent or combinations between them. The review ends with a final outlook and some future perspectives.

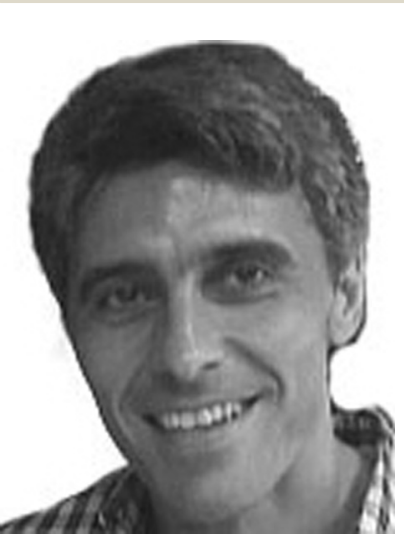

Miguel A. López-Manchado
Miguel A. López-Manchado (MALM) is Research Professor at ICTP-CSIC. He got his PhD in Chemistry at the Complutense University of Madrid in 1997. From 1998-2000, he did a postdoctoral stay at University of Perugia. He got a permanent position as Tenured Researcher at CSIC in 2006. He is author of more than 160 publications in scientific journals and books. His research activity is focused on the processing and characterization of composite materials and nanocomposites.

\section{A brief history of self-healing polymers}

\subsection{Self-healing key concepts}

Inspired by nature, self-healing materials have the ability to repair or restore damage, replicating mechanisms found in living organisms such as plants and human skin. To ensure the success of self-healing, three concepts have been defined by van der Zwaag: ${ }^{12}$ (a) localization, (b) temporality and (c) mobility. We include a fourth key concept: (d) mechanism (Fig. 1), in order to classify the different generations of self-healing materials.

The concept of localization refers to the position and/or scale of the damage in the material. It can be superficial, such as scratches, (micro) cracks, or cuts; it can be deep, such as the propagation of surface damage, fiber debonding or delamination, ending up in catastrophic damage; or it can be molecular scale damage, e.g. breakage of the material network. ${ }^{5}$ The localization and scale of these types of damage play an essential role when considering the self-healing capability of the material. The aim is to reach one single protocol that assures achieving healing at all scales; however, specific protocols can be designed for particular types of damage according to the intended application of the material.

The second factor, temporality, is given by the time gap between the damage event and its repair. Even in nature, selfhealing is time-dependent, not instantaneous. The target is to minimize the time for healing to occur. One way to reduce this time is by conferring mobility to the material, the third key concept. Mobility promotes the diffusion of the healing agent to the damage area, as well as the reformation of the broken bonds. This concept is key to optimize others, e.g. if the mobility of the agent is not adequate, it will not flow towards the damage or it will do so slowly.

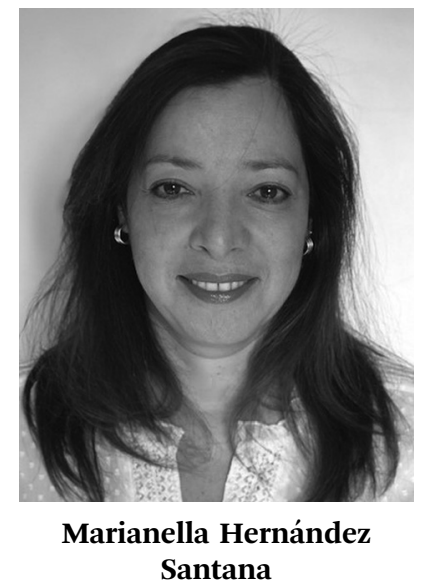

Marianella Hernández Santana (MHS) is Materials Engineer (Simon Bolivar University, Venezuela) with a MSc in Macromolecular Physical-Chemistry (Louis Pasteur University, France) and a PhD in Chemical Sciences (Complutense University of Madrid, Spain). She joined Prof. van der Zwaag's group (Delft University of Technology, Netherlands) as a Marie Curie Fellow developing selfhealing elastomers. Later she returned to Spain to work at the Institute of Polymer Science and Technology (ICTP-CSIC). Since 2019, she holds a Ramon y Cajal position. Her research lines are based on the implementation of circular economy principles, favoring the use of recycled and selfhealing materials. 


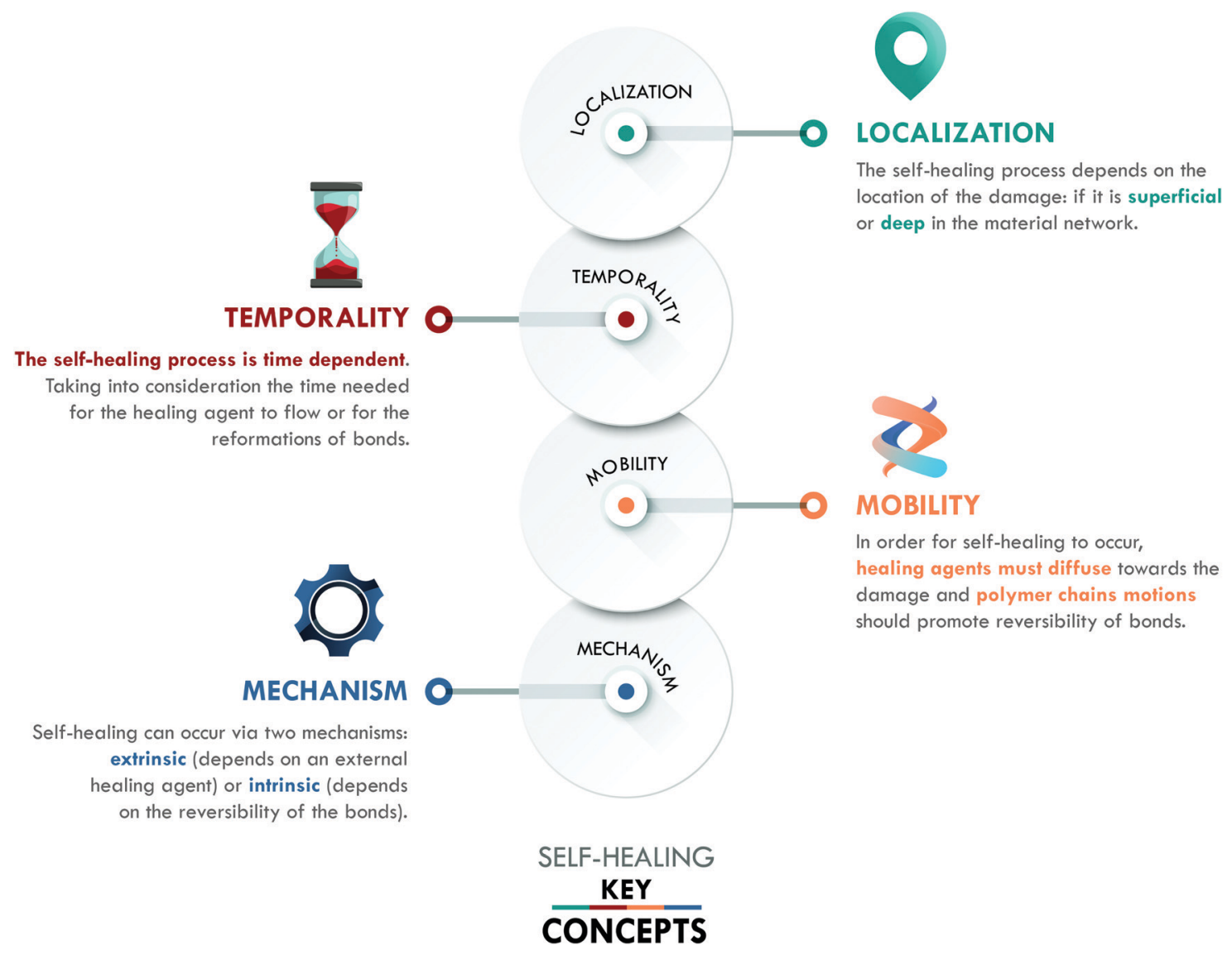

Fig. 1 Self-healing key concepts.

The last key concept in self-healing is the mechanism. This concept enables the classification of self-healing materials into two families: extrinsic and intrinsic. Extrinsic self-healing materials are those in which the process depends on an external agent, normally dispersed in the form of capsules or vascular systems. These agents are released to seal the damage and do not specifically interact with the matrix. On the other hand, intrinsic self-healing materials are those in which the reversible bonds present in the material can be restored after a damage event. ${ }^{5}$ In the case of polymers, extrinsic systems have widely been used in thermosets, mainly in epoxy resins, ${ }^{13-15}$ while intrinsic mechanisms have widely been considered in elastomers, such as silicones, ${ }^{16}$ polyurethanes, ${ }^{17}$ and general purpose rubbers. ${ }^{18-20}$ At this point, it is important to clarify that the current use of the terms intrinsic and extrinsic in the field of self-healing, to classify materials according to the type of mechanism involved, differs from their traditional use to designate physical quantities. In chemistry, intrinsic describes properties independent of size, shape, and quantity (e.g. density and refractive index, among others); meanwhile, extrinsic refers to dependent properties (such as weight and volume). The authors recognize that the use of these terms has some limitations, despite their extensive validation and widespread use in the self-healing field. ${ }^{6,7,10,11,21}$ All of the above has motivated us to propose a new classification, based on the self-healing mechanism and historical development, which enables organizing self-healing materials into four generations (Fig. 2).

Although it was not the first published mechanism (as we will later explain), the first generation of self-healing materials was based on extrinsic mechanisms and employed encapsulated external healing agents. This generation had the disadvantage of only supporting a single cycle of self-healing. ${ }^{6}$ To overcome this limitation, the second generation of selfhealing polymeric materials emerged, based on intrinsic mechanisms, using the chemistry of reversible bonds; however, the self-healing capability and mechanical performance of the materials were in compromise: the increase of one meant the decrease of the other. The intrinsic approach has been studied in all kinds of polymers, with special emphasis in the field of elastomers. ${ }^{7,10}$ Later, further development of extrinsic systems was initiated through healing agents confined in vascular networks, giving way to the third generation of self-healing polymeric materials, with strong inspiration from nature. These systems have been extensively studied in thermosets, but their application in elastomers remains limited except for a few reports on silicones. ${ }^{22}$

Finally, the fourth generation is currently growing fast and aims to overcome the different drawbacks of the previous generations. Hence, its objective is to develop a polymer with excellent mechanical properties, and high healing efficiency 


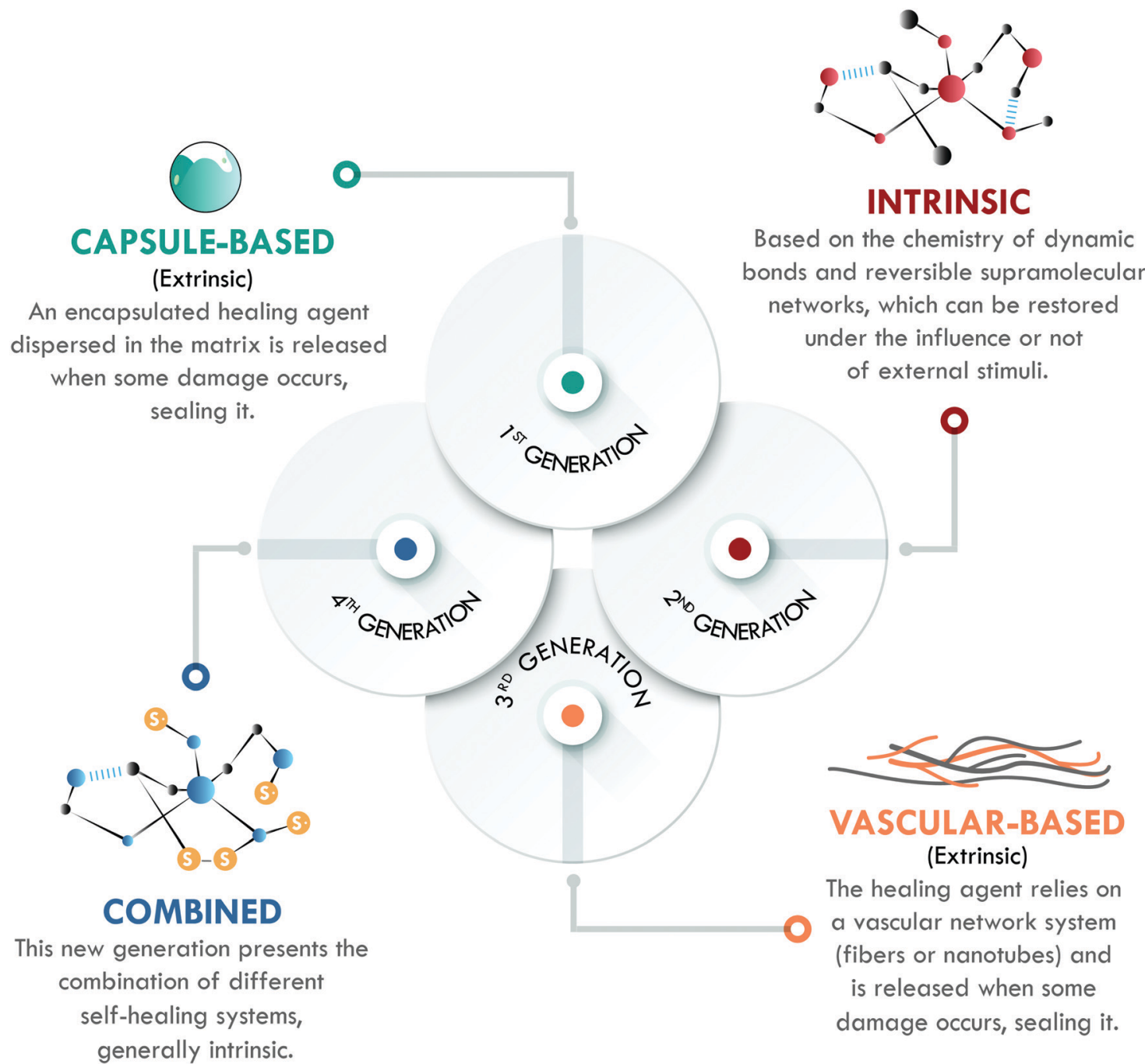

Fig. 2 Generations of self-healing materials according to the healing mechanism involved.

and resistance to multiple damage cycles through the combination of different healing mechanisms. However, the road to this point has been long and there are still some challenges to overcome.

\subsection{Timeline of self-healing polymers}

According to the literature, in the 1970 s, Malinskii et al. ${ }^{23-25}$ presented one of the first studies on polymer self-healing, specifically in poly(vinyl acetate) (PVAc). Later, Jud et $a .^{26}$ and Wool et $_{\text {al. }}{ }^{27,28}$ deepened the study about healing of cracks in poly(methyl methacrylate) (PMMA), polystyrene (PS) and hydroxy-terminated polybutadiene (HTPB). Nevertheless, all these studies and those in the following years were based on chain interdiffusion, ${ }^{29}$ a highly known concept in polymers, which only requires a temperature slightly higher than the glass transition temperature $\left(T_{\mathrm{g}}\right)$ of the material to occur. Ellul et al. ${ }^{30}$ presented the concept of self-adhesion in butyl rubber (IIR), as an essential preliminary step to ensure good contact between the surfaces to be repaired. The concept of autonomic selfhealing, as we know it today, was introduced by Dry et al. ${ }^{31,32}$ in the early 1990s; mainly in cement and epoxy resins. However, it was not until the publication of White et $a l .{ }^{13}$ that the definitive impulse for the development of self-healing polymeric materials began. This work is considered as the starting point of self-healing polymers (Fig. 3). According to White et al. ${ }^{13}$ self-healing was given by the incorporation of a healing agent (dicyclopentadiene, DCPD) embedded in microcapsules and a platinum catalyst (Grubb's catalyst) dispersed in an epoxy resin. Upon the release of the agent and encountering the catalyst, polymerization of the DCPD would occur, sealing the crack. This method, in its initial stage, enabled efficiencies of up to $75 \%$ in the recovery of the maximum load in a fracture toughness test. The implementation of this methodology in elastomers, specifically in poly(dimethylsiloxane) (PDMS), was carried out by Keller et al., ${ }^{33}$ who used a chemistry based on two types of microcapsules. They introduced a high molecular weight resin of PDMS functionalized with vinyl groups and a platinum catalyst in one, while in another they encapsulated an initiator and a PDMS copolymer with active sites that would serve to link the vinyl groups of the functionalized resin by the platinum catalyst action. This chemical reaction, also 


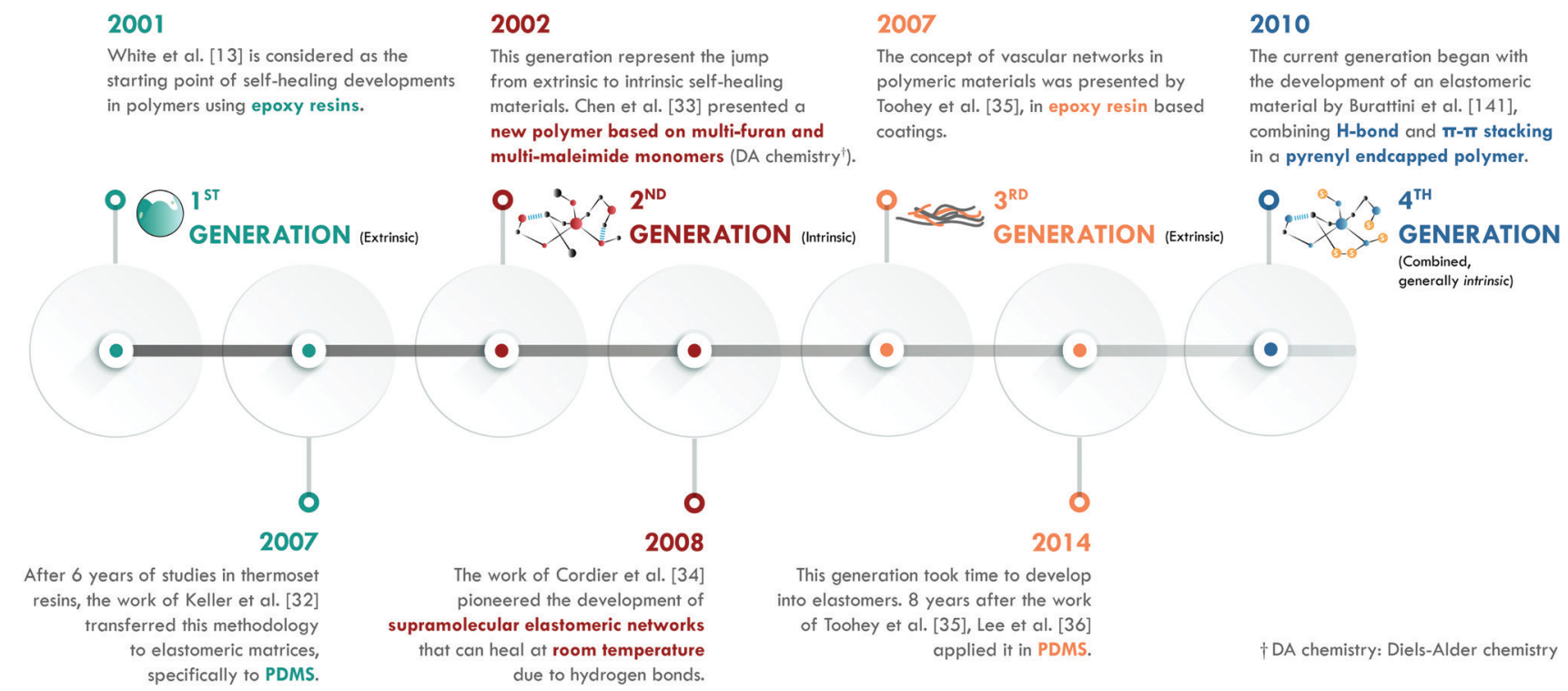

Fig. 3 Timeline of generations in self-healing polymers.

based on the polymerization of external agents, allowed efficiencies of up to $120 \%$ in the recovery of the tear strength. This first generation has been classified in several ways according to the arrangement of the healing agents and catalysts. The most widespread classification comprises five types: single-capsules, capsule/dispersed catalyst, phase-separated droplet/capsules, double-capsules, and all-in-one capsules. It is also possible to establish classifications according to encapsulation techniques (for example: in situ polymerization, sol-gel reaction, interface polymerization, and emulsion, among others). ${ }^{34}$

The second generation is based on the chemistry of the dynamic bonds. Any bond or interaction that is reversible under equilibrium conditions is considered dynamic and can be classified as: covalent and non-covalent. Although polymeric materials based on reversible chemistry had been developed in the past, Chen $e t a l .^{35}$ specifically designed the first self-healing polymer based on multi-furan and multi-maleimide monomers (DielsAlder chemistry). In this work, fracture toughness tests were carried out after healing at temperatures between 120 and $150{ }^{\circ} \mathrm{C}$, achieving an efficiency of $57 \%$ in the recovery of the maximum load. At the same time, the effect of pressure on the repair process was evaluated, concluding that it had a minimal influence on the healing efficiency of this material. This work represented an important development in the field because it showed a recovery of $80 \%$ after subjecting the material to a third healing cycle, thus proving the occurrence of multiple healing cycles.

Years later, Cordier et al $^{36}$ first introduced the intrinsic selfhealing methodology into an elastomer by designing and synthesizing molecules that could form chains and crosslinks through hydrogen bonds. Therefore, they had constructed a supramolecular network that was capable of restoring itself at room temperature. In this work, time dependence in the selfhealing process was evidenced: longer times implied greater efficiencies. At the same time, they concluded that self-healing was not an instantaneous process.
The third generation of self-healing materials began with the work of Toohey et al., ${ }^{37}$ although the concept had been explored almost twenty years earlier by Dry et al. ${ }^{31,32}$ The definitive stimulus for this generation took considerable time, due to the difficulties of incorporating vascular networks into a polymer matrix. This generation is usually classified according to the nature of the vascular network and its preparation technique. For example, electrospinning (coaxial electrospinning or emulsion spinning), solution blowing (coaxial solution blowing or emulsion blowing), and tubes and channel networks (micro/nano, such as hollow glass fibers and carbon nanotubes, among others). ${ }^{22}$ Toohey et al. ${ }^{37}$ used the previously described methodology by White et al. ${ }^{13}$ but the DCPD healing agent was confined in a net embedded in the epoxy resin coating. The healing efficiency was also measured as the retention of properties in fracture toughness tests, with efficiencies of over $40 \%$ and supporting up to 7 healing cycles.

The difficulty of incorporating vascular networks in the matrix has hindered this generation in elastomers. Only one group has reported the incorporation of electrospun vascular networks in PDMS. ${ }^{38-41}$ Lee and coworkers ${ }^{38,39}$ prepared two co-axial electrospun networks with polyacrylonitrile (PAN) as the shell, and with either dimethylvinyl-terminated dimethylsiloxane (resin monomer) or methylhydrogen dimethylsiloxane (curing agent) as the core. Thus, the two core materials only interacted upon cutting the PAN shell. The self-healing efficiency was qualitatively evaluated as an anti-corrosive barrier, showing good performance. Thus, the design of resistant vascular networks that do not break during high shear, conventional processes remains a challenge.

A fourth generation is currently emerging within this field. However, this new generation does not mean that further developments using the previous approaches have stopped. On the contrary, these strategies are largely under development and are under study for both traditional and advanced applications. 
Table 1 Papers published on self-healing rubbers using the first three generations over the last five years

Healing mechanism Rubber matrix Ref.

First generation: capsular self-healing systems

Single-capsule systems

Capsule based

Polyurethane - PU

Double-capsule systems

Capsule based

Polydimethylsiloxane - PDMS

Polyurethane - PU

Capsule based

Second generation: intrinsic self-healing systems Non-covalent systems

Dipole-dipole interactions

Hydrogen bonds

Hydrogen bonds

Hydrogen bonds

Hydrogen bonds

Hydrogen bonds

Hydrogen bonds

Hydrogen bonds

Hydrogen bonds

Hydrogen bonds

Hydrogen bonds

Hydrogen bonds

Hydrogen bonds

Ionic interactions

Ionic interactions

Ionic interactions

Ionic interactions

Ionic interactions

Ionic interactions

Ionic interactions

Ionic interactions

Ionic interactions

Ionic interactions

Metal-ligand coordination

Metal-ligand coordination

Metal-ligand coordination

Metal-ligand coordination

Metal-ligand coordination

Host-guest interactions

Shape memory

Fluorinated elastomer

Epoxidized natural rubber - ENR

Butadiene rubber - BR

Polydimethylsiloxane - PDMS

Polyurea elastomer - PUE

Eucommia ulmoides ester elastomer

Lignin-based supramolecular elastomer

Supramolecular elastomer

Industrial acrylic elastomer

$\mathrm{WSP}^{a}$ - photonic elastomer

Poly(AAm/ChCl-co-MA/ChCl $)^{b}$

Hybrid polymer networks

Conductive elastomer

Natural rubber - NR

Epoxidized natural rubber - ENR

Brominated natural rubber - BNR

Brominated butyl rubber - BIIR

Ethylene propylene diene rubber - EPDM

Polydimethylsiloxane - PDMS

Polyampholyte-based elastomer

NR/BIIR

SBS/EMAA copolymer ${ }^{c}$

Poly(isobutylene-co-isoprene)

Nitrile rubber - NBR

Polydimethylsiloxane - PDMS

Polyurethane - PU

Aminopropyl methyl phenyl polysiloxanes - AMPS

NBR/poly(vinyl chloride)

Alkyl acrylate-based elastomer

ENR/poly(latic acid)

Natural rubber - NR

Styrene butadiene rubber - SBR

Ethylene propylene diene rubber - EPDM

Polydimethylsiloxane - PDMS

Polyurethane - PU

Silicon-based elastomer

Styrene butadiene styrene rubber - SBS

Polymer/graphene-based material

Elastomer coatings

Soft robotics - pneumatic actuator elastomers

Natural rubber - NR

Styrene butadiene rubber - SBR

Butadiene rubber - BR

Chloroprene rubber - CR

Polydimethylsiloxane - PDMS

Polyurethane - PU

Styrene butadiene rubber - SBR

Silicon elastomer

Poly(n-butyl acrylate)

Boronic ester-based polymer

NR latex-based elastomer

Polydimethylsiloxane - PDMS

Epoxidized natural rubber - ENR

Thiol-epoxy elastomer

Poly(butyl methanol methacrylate) - PBMM

Poly(oxime-urethane) - POU

Polyurethane - PU
Ref.

42

49

45 and $50-53$

19

54-60

61

62

63

64-68

69

70

46

71

72

18 and $73-75$

76

77

78-80

81

82 and 83

84

85

86

87 and 88

89

16 and 90-98

99

100

101

102

103

104

105

106

107-111

17 and 112-118

119 and 120

121-123

124

125

126-130

131-133

20 and 134

135 and 136

137

138 and 139

140 and 141

142

143

144

145

44

146-148

149-151

152

153

154

155 
Table 1 (continued)

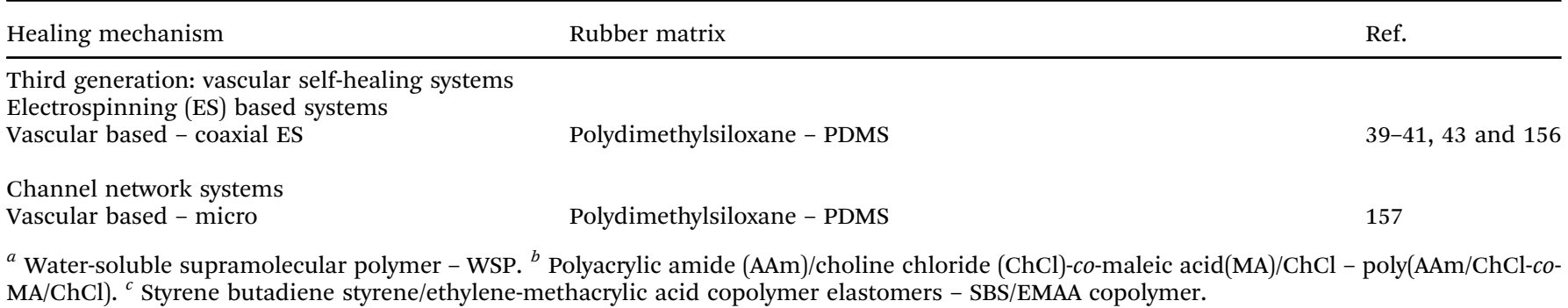

For example, the use of extrinsic mechanisms has shown a notable increase in coatings, ${ }^{39}$ instrument panels, ${ }^{42}$ and sponges, ${ }^{43}$ while intrinsic ones have turned out to be more versatile for general purpose elastomers in innovative applications such as nanogenerators, ${ }^{44}$ sensors, ${ }^{45}$ conductive elastomers, ${ }^{46}$ and even tires. ${ }^{20}$ Table 1 summarizes some examples of the published work in the last five years in self-healing rubbers based on the first three generations.

Despite all this work, the dichotomy between mechanical properties and self-healing efficiency is still an unresolved challenge. The combination of healing mechanisms as a way of positively balancing these two parameters is the core of the fourth generation.

\section{Fourth generation of self-healing rubbers}

Since the work of Burattini et al. ${ }^{158}$ the literature on combined self-healing mechanisms is steadily growing (Fig. 4), and has focussed on intrinsic self-healing mechanisms, always searching for an optimal combination of dynamic bonds, either covalent (those that require a stimulus for reversibility) or non-covalent (those that are intrinsically reversible due to their lability). ${ }^{159}$ Such a strategy has also been considered for different, but not distant, purposes in elastomers, such as recyclability; ${ }^{160-163}$ however, this section concentrates on self-healing articles. Table 2 summarizes the publications of the fourth generation of self-healing rubbers, where $\sigma_{\mathrm{R}}$ refers to the tensile strength

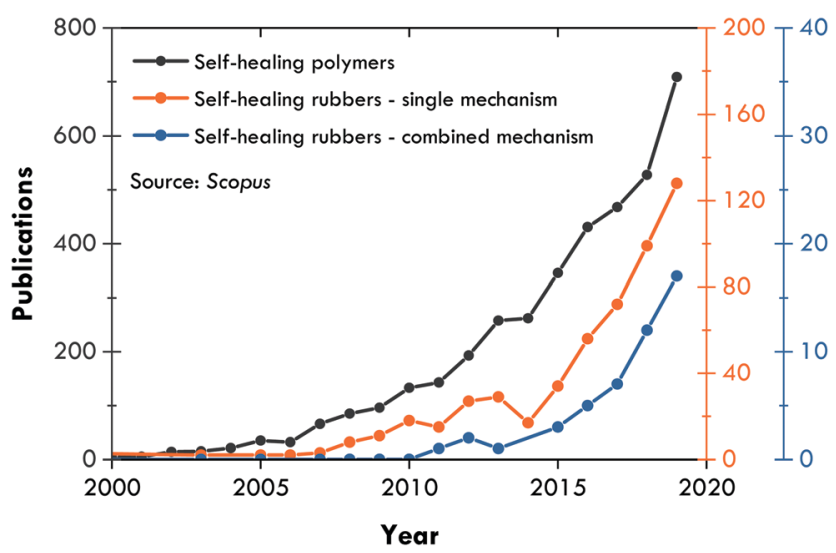

Fig. 4 Evolution in the number of publications on self-healing rubbers. prior to healing, $\eta$ is the healing efficiency, and $T$ is the temperature at which the healing was performed. The discussion of this review is focused on these characteristics.

\subsection{Combined non-covalent systems}

Intrinsic self-healing mechanisms of non-covalent nature comprise all those weak interactions that can occur between different families of atoms, such as van der Waals interactions, $\pi-\pi$ stacking, dipole-dipole interactions, hydrogen bonding, ionic interactions, metal-ligand coordination and host-guest interactions. Some authors ${ }^{208,209}$ attribute self-healing capability to the existence of the shape memory effect (SM). It is not clear if SM can be considered as a self-healing mechanism itself. We have included it in this section because, without a doubt, it assists the self-healing process, especially in its initial stages, when the best possible contact between the surfaces is required, contributing to achieving high healing efficiencies. Fig. 5 summarizes all non-covalent interactions and their basic definition.

Non-covalent systems are characterized by having low bonding energy compared to pure covalent systems, ${ }^{216}$ so they usually have higher healing efficiencies since this facilitates the restoration of the broken bonds even at room temperature. The non-covalent interaction most used in elastomers is based on hydrogen bonds, which have been combined with other interactions of the same nature to design self-healing materials with diverse performances. Burattini et al. $^{158}$ reported a combination of healing moieties ( $\pi-\pi$ stacking and hydrogen bonds) in an elastomeric network based on polyimide and polyurethane with pyrenyl end groups. The $\pi-\pi$ stacking was due to the $\pi$-electron-deficient diimide groups and the $\pi$-electron-rich pyrenyl units. Meanwhile, the formation of hydrogen bonds occurred at the intermolecular level, between the terminal residues of the pyrenyl groups in polyurethane. This material reached a tensile strength of $0.2 \mathrm{MPa}$, with a healing efficiency higher than $80 \%$ with respect to the tensile strength. Following the same combination of intrinsic mechanisms, Zuo et al. ${ }^{164}$ designed, for the first time, a fluorescent polysiloxane-based elastomer with $60 \%$ healing efficiency at room temperature and a tensile strength of $3.28 \mathrm{MPa}$. In this study, supramolecular interactions were confirmed through molecular simulation. The prepared materials presented interesting potential for bioimaging purposes.

The second most commonly used non-covalent mechanism employs ionic interactions. Xu et al. ${ }^{165}$ successfully combined 
Table 2 Fourth generation of self-healing rubbers

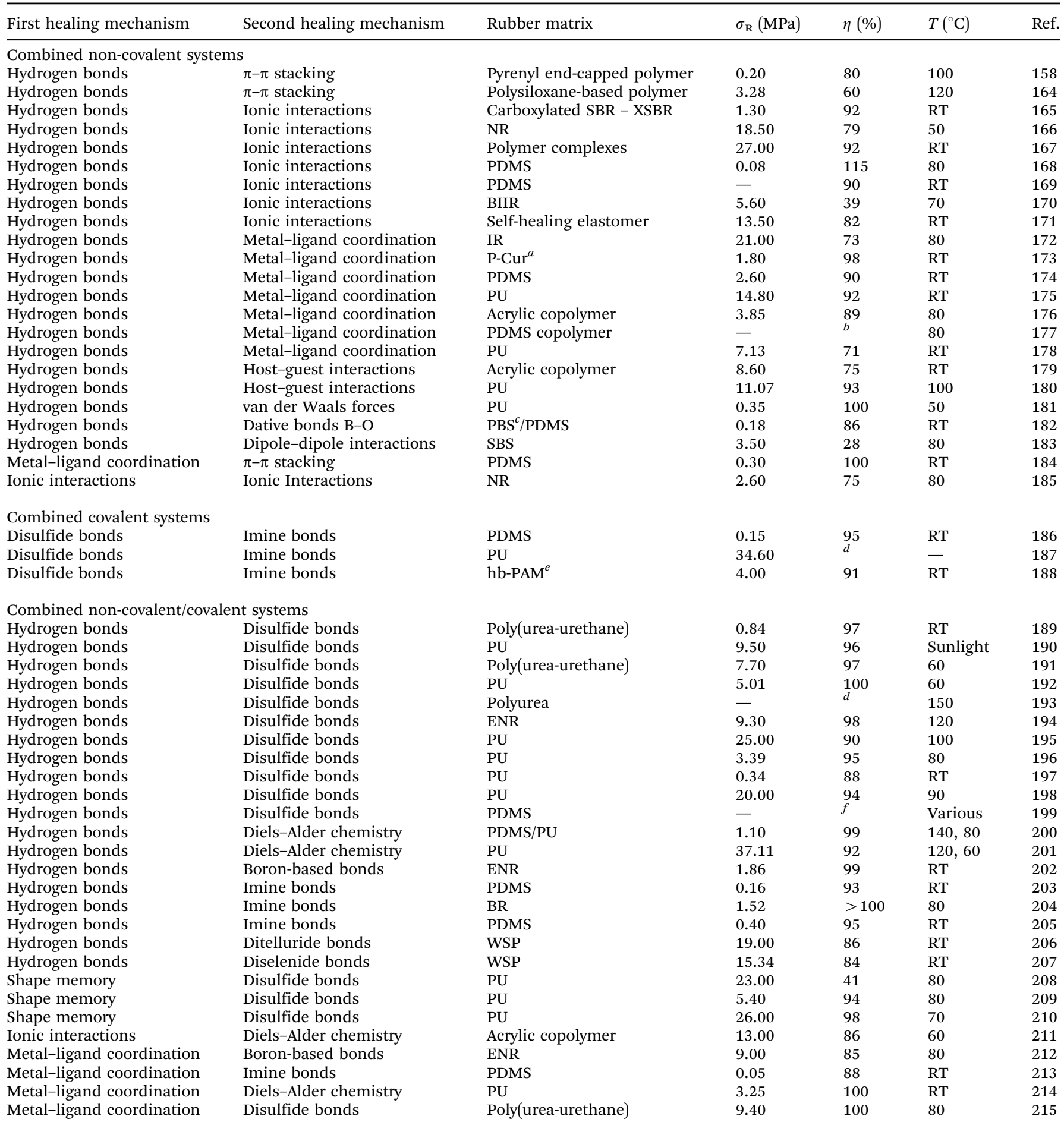

${ }^{a}$ Curcumin polymer block - P-Cur. ${ }^{b}$ The self-healing process was only qualitatively evaluated by profilometry. ${ }^{c}$ Poly(butylene succinate) - PBS. ${ }^{d}$ The self-healing process was evaluated by optical microscopy under different external stimuli. ${ }^{e}$ Hyperbranched polyazomethine - hbPAM. ${ }^{f}$ The self-healing efficiency was calculated for the elongation at break.

them with hydrogen bonds in a carboxylated styrene-butadiene rubber (XSBR) filled with chitosan nanoparticles. The formation of ionic clusters enabled the configuration of a crosslinked supramolecular network with reversible bonds at room temperature that reached healing efficiencies of up to $92 \%$ with a tensile strength of 1.3 MPa. Sattar et al. ${ }^{166}$ used this same combination for the first time to prepare silica filled $\left(\mathrm{SiO}_{2}\right)$ natural rubber (NR) compounds. Their strategy involved the ionization of the natural proteins and lipids of the elastomer to produce the ionic crosslinks. The dynamic supramolecular network was 


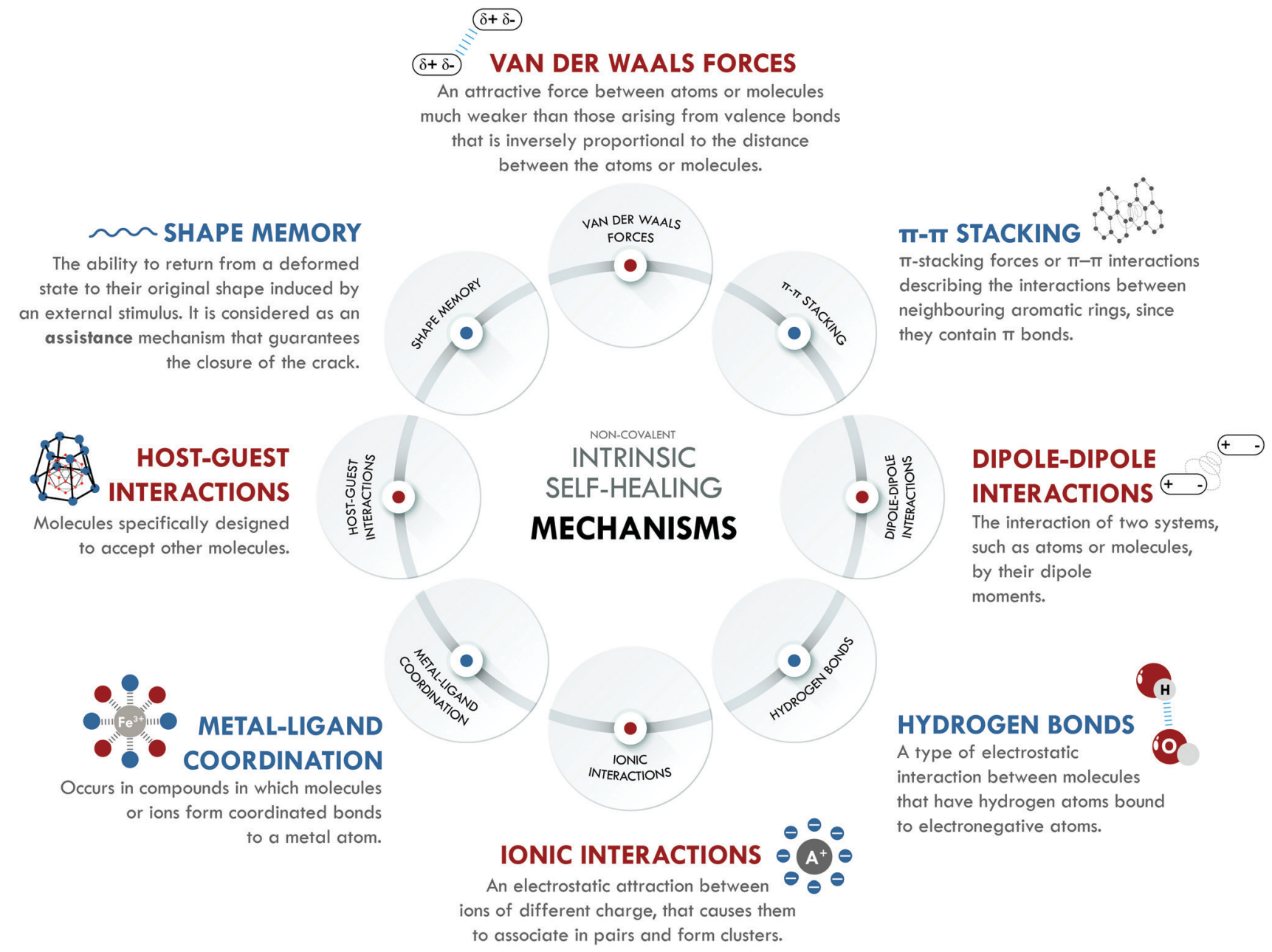

Fig. 5 Non-covalent intrinsic self-healing mechanisms.

formed by adding magnesium sulfate $\left(\mathrm{MgSO}_{4}\right)$, which provided $\mathrm{Mg}^{2+}$ ions, and formed electrostatic pairs with the negative charged lipids, arising from the acidic ionization. This procedure resulted in healing efficiencies of $79 \%$ at $50{ }^{\circ} \mathrm{C}$ with an excellent tensile strength of 18.5 MPa. The formation of the ionic network was confirmed by Fourier-transform infrared spectroscopy (FTIR) and by comparison with deproteinized $\mathrm{NR}$, in which the repair efficiency was only $52 \%$.

Combined hydrogen bonds and ionic bonds were also considered by Guo et al., ${ }^{167}$ giving rise to a non-covalent network with the highest tensile strength and the best resistance/ efficiency ratio reported. They prepared ternary polymer complexes of branched poly(ethyleneimine) (bPEI), poly(acrylic acid) (PAA) and poly(ethylene oxide) (PEO) (bPEI/PAA/PEO). These ternary complexes facilitated the formation of electrostatic interactions, between the bPEI and PAA, and of hydrogen bonds, between PAA and PEO (Fig. 6). Thanks to a positive effect between both interactions, an elastomeric material was obtained with a tensile strength of $27.4 \mathrm{MPa}$ and a healing efficiency of $92 \%$ at room temperature in a high humidity atmosphere. More recently, the same joint mechanisms were explored in a special purpose rubber, brominated butyl rubber (BIIR), with opposite results. Stein et al. ${ }^{170}$ designed an elastomeric network of BIIR modified with one uracil and one imidazole moiety. The latter provided the ionic groups that associate in so-called ionic clusters, while the former, with a bifunctional structure containing two diamidopyridyl moieties, was responsible for the formation of hydrogen bonds. The incorporation of hydrogen bonds worsened the healing efficiency achieved with only ionic interactions, since they decreased the tensile strength to $5.7 \mathrm{MPa}$ and the healing efficiency to $39 \%$ from a tensile strength of 10.7 MPa and a healing efficiency of $74 \%$ at $70{ }^{\circ} \mathrm{C}$.

The metal-ligand coordination bond is another noncovalent option widely combined with hydrogen bonds. One of the most relevant studies was performed by Liu et al. ${ }^{172}$ They reported poly(isoprene) (IR) with unprecedented mechanical properties, $21 \mathrm{MPa}$, and good healing efficiency, $72 \%$ at $80{ }^{\circ} \mathrm{C}$. These results were attributed to three factors: first, to the dynamic nature of both mechanisms; second, to the mobility of the IR chains, which facilitated self-healing at the selected temperature and time; and third, to a positive effect thanks to the combined mechanisms (Fig. 7).

These dual mechanisms were also reported in polyurethane (PU). PU and its variants are the most studied materials from 

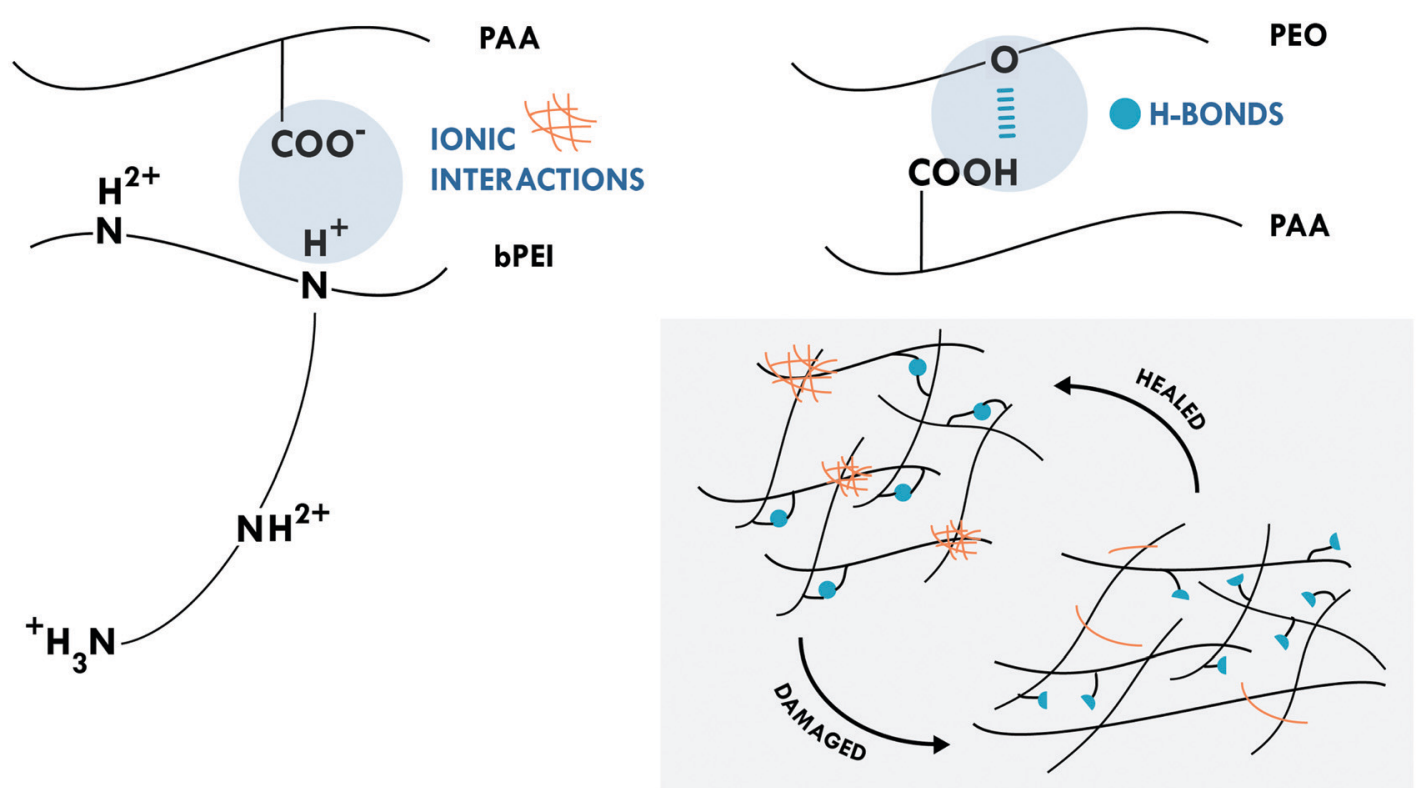

Combined mechanisms:
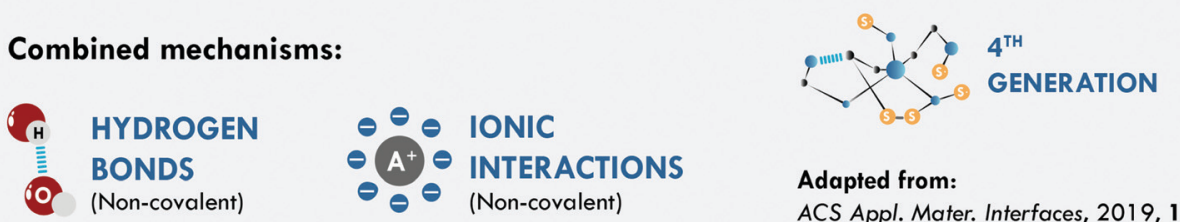

Adapted from:

ACS Appl. Mater. Interfaces, 2019, 11, 33356-33363.

Fig. 6 Combination between hydrogen bonds and ionic interactions in bPEI/PAA/PEO. ${ }^{167}$ (C)2019. Adapted with permission from the American Chemical Society.

the point of view of intrinsic mechanisms, so it is not surprising that it is one of the first materials in which a network with three types of dynamic bonds has been reported: one covalent and two non-covalent, the latter being responsible for selfhealing at room temperature. Zhang et al. ${ }^{175}$ prepared a $\mathrm{Cu}(\mathrm{II})$ dimethylglyoxime-urethane-complex-based polyurethane elastomer. Here, the metal-ligand coordination was given by the copper ions and the hydrogen bonds were between amino groups and esters of the main chain. A tensile strength of 14.8 MPa and an efficiency of $92 \%$ were achieved, with potential applications in wires.

In PU, two other mechanisms together with hydrogen bonds have also been reported: host-guest interactions and van der Waals forces, with very different results. Xiao et al. ${ }^{180}$ designed a network based on the combination of host-guest interactions and multiple hydrogen bonds in waterborne PU (WBPU), an environmentally friendly option that decreases the effect of the release of volatile organic components into the atmosphere. They reported a tensile strength of $11.07 \mathrm{MPa}$ and efficiency of $93 \%$, close to the work described above with metal-ligand coordination, but at a temperature of $100{ }^{\circ} \mathrm{C}$. On the other hand, Chen et al. ${ }^{181}$ combined hydrogen bonds with van der Waals forces in poly(urethane urea) (PUU) in which a branched poly(propylene carbonate) (PPC) diol was used as the soft segment, obtaining a tensile strength of $0.35 \mathrm{MPa}$, with $100 \%$ healing efficiency at $50{ }^{\circ} \mathrm{C}$. The origin of these results was ascribed to the bond energy of the van der Waals force, which is considerably low compared to other non-covalent mechanisms.

In summary, there is no clear tendency in the effect of combined non-covalent systems on healing and mechanical performance. Both properties seem to be strongly influenced by the energy of the selected bonds, the chemical structure of the matrix and the effect generated when combining different mechanisms. Moreover, not all the combinations are a priori useful; the positive combination effect clearly depends on the matrix and the competition between the interactions.

\subsection{Combined covalent systems}

Intrinsic covalent mechanisms are related to all those chemical bonds that can be formed between different atoms and can be dynamic under an external stimulus. Fig. 8 schematically summarizes some of these bonds and their basic definition. Clear examples are disulfides, which can undergo metathesis reactions, or Diels-Alder chemistry, where Diels-Alder and retro-Diels-Alder reactions occur at different temperatures. These bonds are of higher energy compared to non-covalent bonds, ${ }^{216}$ so their contribution is usually associated with the mechanical performance of the material. However, their reversibility is a key factor in achieving high healing efficiencies.

The combination of covalent systems has been mildly reported with only two articles in recent years, using the same dual system with disulfide and imine bonds. Lv et al. ${ }^{186}$ applied 

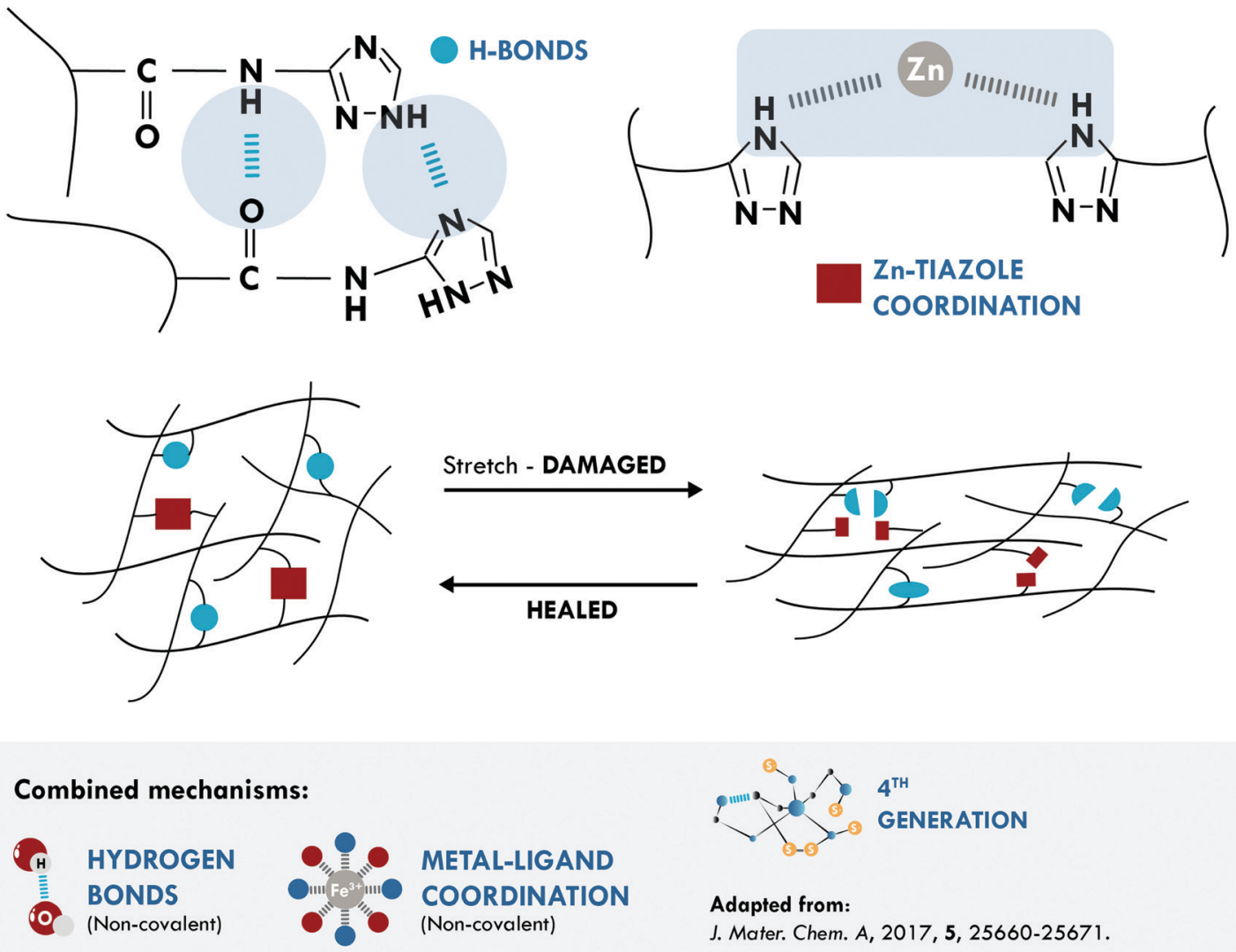

Adapted from:

J. Mater. Chem. A, 2017, 5, 25660-25671.

Fig. 7 Combination between hydrogen bonds and metal-ligand coordination in IR. ${ }^{172}$ (C)2017. Adapted with permission from the Royal Society of Chemistry.

aromatic disulfides, whose metathesis can occur at room temperature, contrary to aliphatic disulfides, which require an external stimulus. They obtained PDMS that could be repaired in just $4 \mathrm{~h}$; however, its mechanical properties, typical of siloxane-based systems, were merely 0.15 MPa. Self-healing is mainly ascribed to the disulfide bond, which acted as a sacrificial bond, while the imine bond would mostly act as semi-permanent crosslink points for the elasticity and maintaining the original shape. Although the mechanical strength is low, this work serves as a proof of concept for certain applications (e.g. adhesives), in which high mechanical performance is not necessary. Lee et $a .^{187}$ used the same approach in PU, studying the metathesis of both dynamic bonds (Fig. 9). The elastomer preparation was carried out in two stages; first, they prepared a Schiff base from biomaterials such as cystine and vanillin, responsible for providing disulfide and imine bonds. Subsequently, the base was mixed with 1,4-butanediol (to ensure miscibility) and added to the precursors of PU (isophorone diisocyanate, IPDI, and poly(propylene glycol)based thiol, PPG). They monitored the healing process through optical microscopy and reported complete healing of cracks in 120 min with the use of heat $\left(65^{\circ} \mathrm{C}\right)$ and UV irradiation. The material also exhibited a recyclability efficiency of $97 \%$ but the healing efficiency was not reported as a measure of the retention of tensile properties.
The limited literature of combined covalent-based mechanisms is a clear indication that these dual systems are not the preferred option in elastomeric matrices, nor in any other type of polymer. We can speculate and attribute such low development to two facts. On one side, the imperative need for an external stimulus (in most cases) for assuring the reversibility of the covalent bonds. On the other side, the high bond energy that limits molecular dynamics and, thus, partially restricts reversibility and healing.

\subsection{Combined non-covalent/covalent systems}

The combination of covalent and non-covalent bonds is one of the most explored systems among the fourth generation, obtaining materials with good mechanical performance and high healing efficiencies. For these dual systems, we can observe a prevalence of PU as a material, and hydrogen bonds/disulfide bonds as a designated combination. Rekondo et al. ${ }^{189}$ were the first to apply this strategy and used aromatic disulfide metathesis to design a self-healing network of PUU. They reached $97 \%$ healing efficiency thanks to the aromatic disulfides, which are in constant exchange at room temperature, and to the urea groups, which can form quadruple hydrogen bonds. However, the mechanical properties were limited for high-performance applications. Xu et al. ${ }^{190}$ solved this limitation by developing an interesting system where healing was promoted by sunlight, with potential application in the manufacture of smart photosensitive 


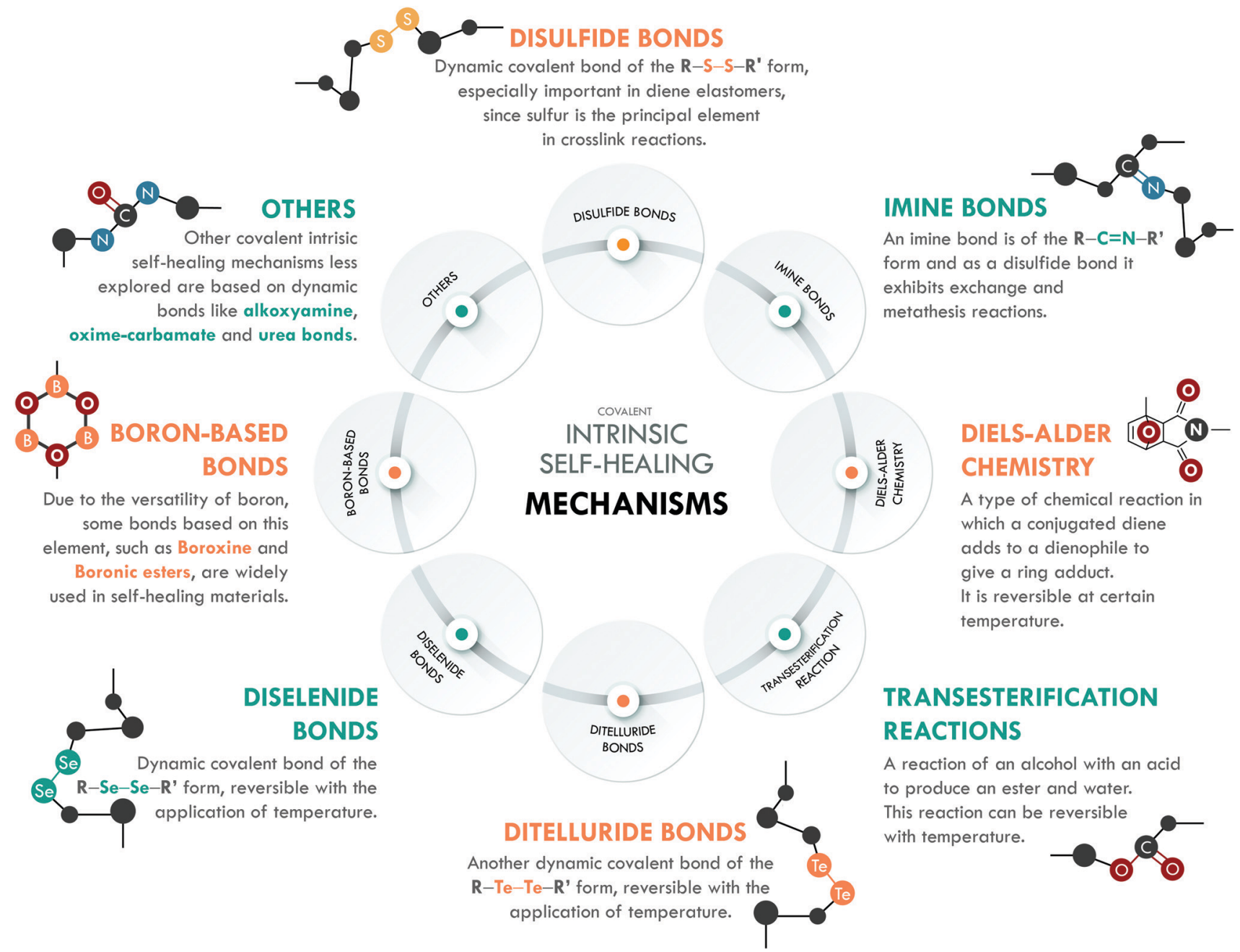

Fig. 8 Covalent intrinsic self-healing mechanisms.

polymers with high tensile strength. Although pure UV light was known to generate disulfide exchange, it was unknown if the low UV content in sunlight (between 3\% and 5\%) would be able to generate the same effect. They demonstrated, by mass spectroscopy and liquid chromatography (HPLC), that the UV component of sunlight was capable of generating a photochemical exchange reaction of disulfides in small molecules. Here, this exchange was favored by the formation of hydrogen bonds between amino groups adjacent to the disulfide groups of the main chain. They reported healing efficiencies of up to $96 \%$ with a tensile strength of 9.5 MPa. The development of PU with enough mechanical robustness continued to grow. Hu et al. ${ }^{195}$ introduced 2-ureido$4[1 H]$-pyrimidione (UPy)-functionalized side groups in the hard segment of thermoplastic polyurethane (TPU). The introduction of these functional groups formed quadruple hydrogen bonds and generated a supramolecular network that increased the crosslink density of the hard domains. The result of this combination was a material with a tensile strength of $25 \mathrm{MPa}$ and a healing efficiency of $90 \%$ at a temperature of $100{ }^{\circ} \mathrm{C}$.

All these advances in PU have enabled its use in innovative applications, such as 3D printing, which seems quite distant for other elastomeric materials. Li et al. ${ }^{196}$ reported one of the first examples of self-healing PU manufactured using digital light 3D printing (DLP), with potential application in the manufacture of sensors and flexible electronics. Their elastomer reached a tensile strength of $3.39 \mathrm{MPa}$ with a healing efficiency of $95 \%$ after $12 \mathrm{~h}$ at $80^{\circ} \mathrm{C}$. At the same time, they proved that the material supports multiple healing cycles. The healing protocol was applied directly on a piece produced with a honeycomb structure, which corroborated the applicability and success of the designed system, being able to bend freely and withstand high deformation without failing.

More recently, Liu et al. ${ }^{198}$ continued exploring different options on PU under this combination of healing mechanisms. They incorporated poly(vinyl alcohol)-graft-( $\varepsilon$-caprolactone) (PVA-PCL) into isocyanate terminated PU with disulfide bonds. The incorporation of PVA-PCL increased the formation of hydrogen bonds, which acted as physical crosslink points. They reported an improved tensile strength, of $20 \mathrm{MPa}$, and a positive effect of the hydrogen and disulfide bonds on the healing efficiency, reaching $94 \%$ at $90{ }^{\circ} \mathrm{C}$. All the work done with PU highlights the good balance that can be reached 


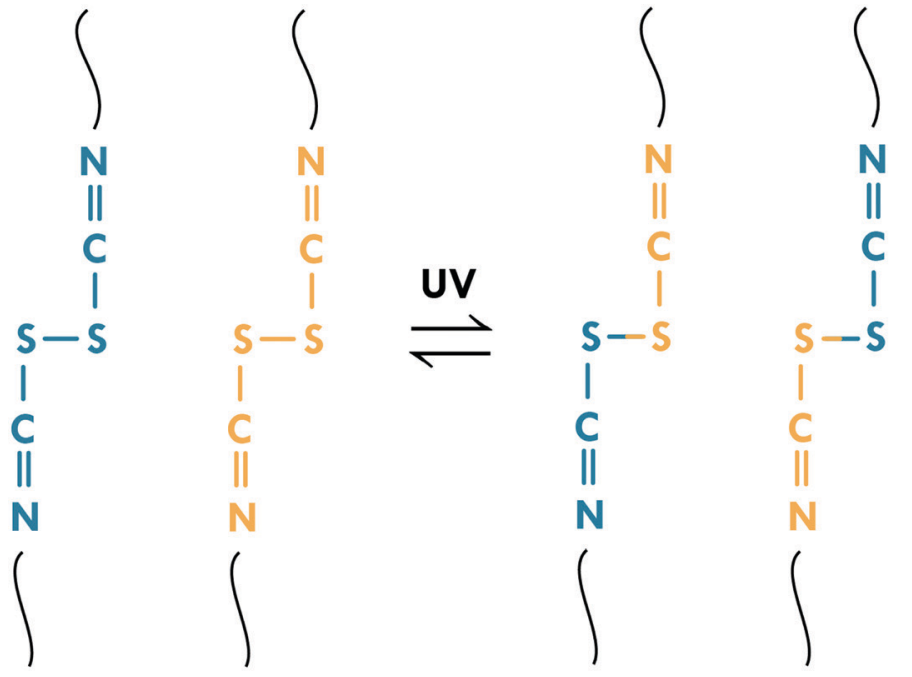

DISULFIDE METATHESIS

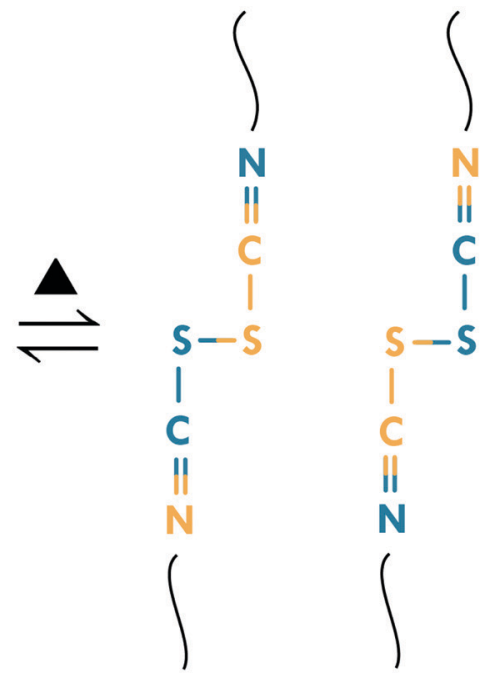

IMINE + DISULFIDE METATHESIS

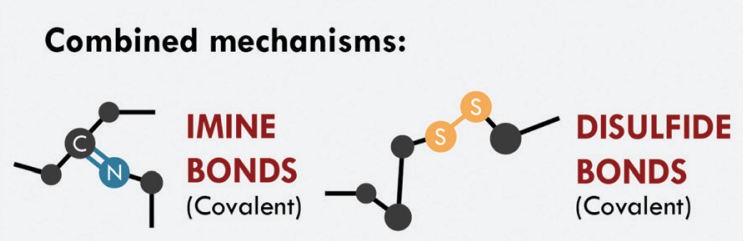

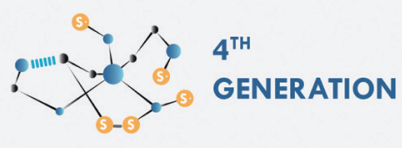

Adapted from:

Mater. Des., 2019, 5, 25660-25671.

Fig. 9 Imine and disulfide metathesis in PU. ${ }^{187}$ (C)2019. Adapted with permission from Elsevier.

between mechanical performance and healing capability. However, in most cases the healing procedure applies high temperatures $\left(>60{ }^{\circ} \mathrm{C}\right)$. Thus, room temperature self-healing is still a milestone to overcome in the development of high performance PU.

The second most studied system is a general purpose elastomer, in particular epoxidized natural rubber (ENR). Cheng et al. ${ }^{194}$ considered two known principles: the vulcanization of the double bond of the main chain of cis-1,4 poly(isoprene) and the opening reaction of the epoxy ring. They performed a typical vulcanization reaction, to create multiple sulfur bonds in the main chain, together with the addition of aromatic disulfides, to couple to the radical generated during the ring-opening reaction (Fig. 10). Simultaneously, the ringopening reaction generated multiple hydroxyl groups forming hydrogen bonds that assist the self-healing process. This combination resulted in a tensile strength of $9.30 \mathrm{MPa}$ and $98 \%$ healing efficiency at $120{ }^{\circ} \mathrm{C}$, compared to only $22 \%$ of an equivalent disulfide-free sample.

The metathesis reaction can also occur in other bonds formed by chalcogens (elements of group 16 of the periodic table, like sulfur). Fan et al. studied the exchange of ditelluride ${ }^{206}$ and diselenide. ${ }^{207}$ In both cases, water-dispersed supramolecular polymers (WSP) were prepared with aliphatic molecules with exchangeable bonds and pendant UPy groups. The latter, as shown in other studies, are capable of forming quadruple hydrogen bonds, with an important contribution to the mechanical properties and healing efficiency. This system resembled that of hydrogen and disulfide bonds, but with an interesting contribution: the exchange reaction occurred thanks to visible light. Both studies reported tensile strengths between 15 and $19 \mathrm{MPa}$ with healing efficiencies around $85 \%$ at room temperature.

In 1950, Otto Diels and Kurt Alder received the Nobel Prize in Chemistry for their work on diene reactions. ${ }^{217}$ More than half a century later, Diels-Alder (DA) chemistry has widely been used in the design of dynamic networks to overcome the irreversibility of most crosslink reactions. ${ }^{218}$ Hence, it is not surprising that this chemistry represents one of the main mechanisms used in the design of self-healing materials. The DA reaction has been combined with hydrogen bonds for the design of two self-healing materials. Zhao et al. ${ }^{200}$ applied it in poly(siloxane-urethane). In one case, they used isocyanate terminated PDMS combined with a DA diol (PDMS-DA-PU), while in a second case, they employed mixtures of the isocyanate terminated PDMS with a PCL diol and a DA diol (PDMS/PCL-DAPU) (Fig. 11). Following the evolution of a crack, they concluded that the PCL system hindered the repair; however, it increased the stiffness of the soft segments. Meanwhile, the sample without PCL allowed total healing of the crack, recovering $96 \%$ of their initial tensile stress (1.1 MPa) compared to $83 \%$ efficiency of the PDMS/PCL-DA-PU samples (tensile strength of $3.25 \mathrm{MPa}$ ). The low mobility of PCL hindered the approach of the furan and maleimide groups to reform the DA adduct, but the hydrogen 


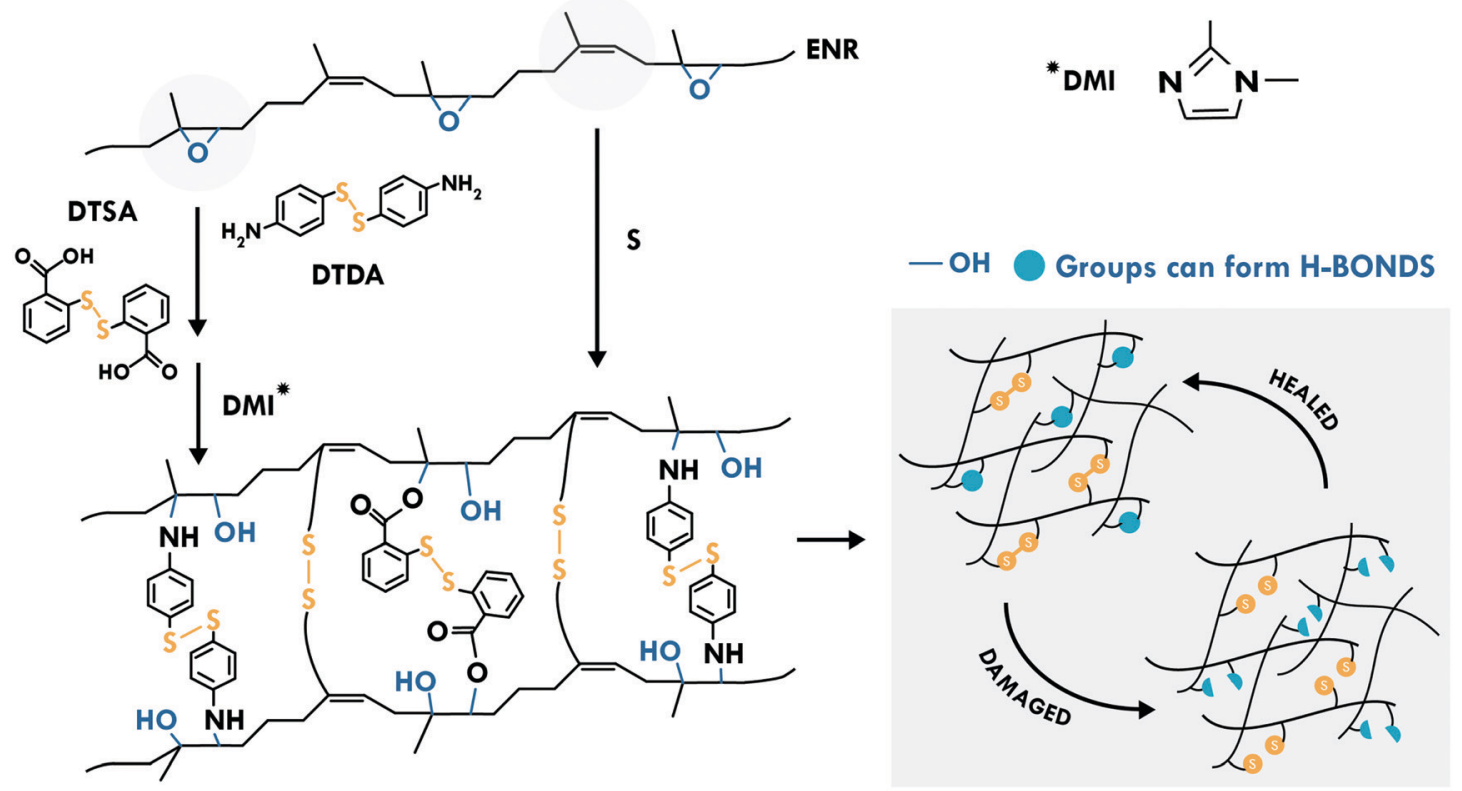

\section{Combined mechanisms:}

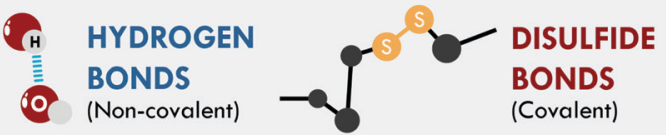

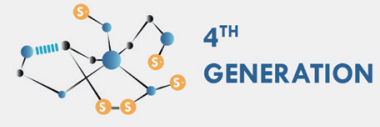

Adapted from:

ACS Sustainable Chem. Eng., 2019, 7, 4443-4455.

Fig. 10 Combination between disulfide and hydrogen bonds in ENR. ${ }^{194}$ C2019. Adapted with permission from the American Chemical Society.

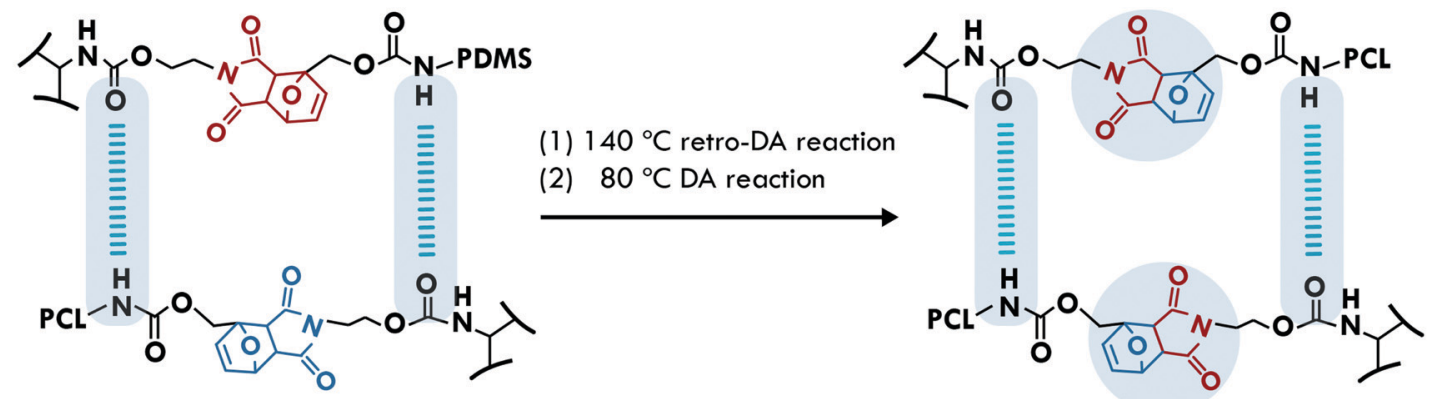

Combined mechanisms:
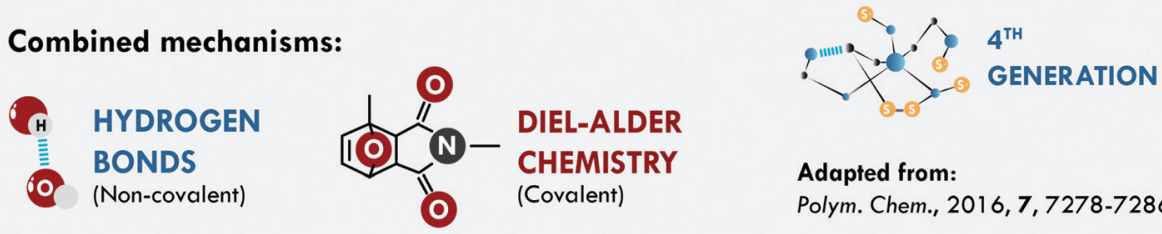

Adapted from:

Polym. Chem., 2016, 7, 7278-7286.

Fig. 11 Combination between DA chemistry and hydrogen bonds in PDMS-DA-PU. ${ }^{200}$ (C)2016. Adapted with permission from the Royal Society of Chemistry

bonds could compensate and maintain a good healing efficiency with a considerable increase in the mechanical properties. Besides, the biocompatibility of the material was proved by cytotoxicity evaluation and animal wound healing experiments, making it a good candidate for applications of smart self-healing artificial skin.

Yang et al. ${ }^{201}$ also explored the combination of DA chemistry with hydrogen bonds. They prepared a reversible dual network 
by combining tri(2-furyl) phosphoramide (TFP) with a maleimide end-capped PU elastomer (MPU). With a precise stoichiometric relationship, these systems enabled the crosslinking of PU with TFP via DA chemistry. The healing mechanism comprised three stages: the rupture of the DA adduct through the rDA reaction at high temperature; then, the diffusion of the TFP and PU chains along the damaged surface; and, finally, the reformation of the DA bonds and hydrogen bonds between the hard segments of MPU and between MPU and TFP at $60{ }^{\circ} \mathrm{C}$. This results in a selfhealing elastomer with unprecedented mechanical properties (37.11 MPa) and a healing efficiency of $92 \%$.

Another dynamic covalent link combined with hydrogen bonds is the boroxine bond. Guo et al. ${ }^{202}$ modified an ENR matrix with 3-aminophenylboronic acid (APB). This introduced a functionality with pendant secondary amines and boronhydroxyl groups thanks to the ring-opening reaction of the epoxy ring. The formation of boroxine bonds between the boron and hydroxyl groups, through the dehydration reaction, and the formation of hydrogen bonds between the secondary amines, gave the material a reversible character. This rubber exhibited a healing efficiency of $91 \%$ at room temperature (based on toughness) and, even after 10 healing cycles, continued to reach high efficiencies $(71 \%)$, this reduction being attributed to the irreversible rupture of covalent bonds after each test. This material not only exhibited great self-healing performance, but also generated a fluorescent response under deformation and showed sensitivity to external stimuli such as strain and humidity. They also tested the material in the throat of a volunteer and observed the strain-dependent sensing of different sounds and expressions, proving its potential application to identify human actions.

The imine bond has also been used repeatedly for the development of dual elastomeric networks with hydrogen bonds, mainly in PDMS. Yan et al. ${ }^{203}$ developed a network with high elongation and healing efficiency, $93 \%$ at room temperature, capable of being repaired at low temperatures, such as $-20{ }^{\circ} \mathrm{C}$. This study is one of the few cases that considered freezing temperatures in self-healing. Meanwhile Yang et al. ${ }^{205}$ reported the creation of a PDMS sensor with a healing efficiency of more than $70 \%$ at room temperature and in different media such as air, water and artificial sweat. These sensors were capable of detecting human movements. Hence, the use of self-healing silicones as soft electronics and sensors and in other applications that do not require high mechanical properties is a very promising field.

All the studies described above involved the use of hydrogen bonds as the non-covalent contribution; however, they are not the only system used. Shape memory has also been shown to facilitate self-healing. Xu et al. ${ }^{208}$ and Chang et al. ${ }^{209}$ used it in combination with disulfide bonds to develop PU. In both cases, shape memory eliminated the gap between the two areas of the damaged surface, guaranteeing good contact and ensuring high healing efficiency. Other non-covalent systems were used as ionic interactions combined with DA chemistry in an acrylic copolymer. ${ }^{211}$ In the last year, metal-ligand coordination has also been combined with different covalent systems and matrices such as ENR (with boron-based bonds ${ }^{212}$ ), PDMS (with imine bonds ${ }^{213}$ ), PU (with DA chemistry ${ }^{214}$ ) and PUU (with disulfide bonds ${ }^{215}$ ), but with very different results that limit establishing yet a clear trend for these combinations.

\section{Outlook and perspectives}

This minireview has defined what we dubbed "generations of selfhealing materials", providing a short overview of their evolution and focusing on the latest advances in the field. Thus, it has been shown that over the last twenty years self-healing materials have evolved from simple systems that only supported a single healing cycle to systems capable of: supporting multiple cycles; being activated through sunlight, UV light or temperature; being repaired in different media than air; or being healed at room temperature within a few minutes. Remarkably, all these systems can be processed using conventional techniques and with more innovative methods such as $3 \mathrm{D}$ printing.

These improvements have mostly arisen over a short period of time with the development of the fourth generation of self-healing materials. These systems have evolved from the knowledge gained over previous generations, which are still under study. They are based on the combination of different healing mechanisms and could represent the path for making the definitive jump to commercial applications. One plausible explanation for the success of this approach is that covalent and non-covalent mechanisms complement each other: dynamic covalent bonds bring considerable improvements in mechanical properties and partially contribute to the self-healing capability, while non-covalent interactions act as the main sacrificial bonds providing substantial progress to the healing efficiency. In the near future, combinations will surely not be limited to two mechanisms, but it is likely that multiple combinations will be explored (three or more), seeking further positive effects. ${ }^{219}$ The use of fillers or other additives as carriers of additional healing mechanisms could also be a promising option, ${ }^{220,221}$ while molecular dynamics studies seem mandatory for simulating interactions between combined mechanisms and for predicting their effect on the self-healing capability. ${ }^{181,222-224}$

Fig. 12 shows the evolution between generations with a general and not-material specific trend towards self-healing elastomers with excellent mechanical performance (tensile strength higher than $10 \mathrm{MPa}$ ) and healing efficiencies higher than $80 \%$ in the absence of external stimuli. Special attention should be paid to general-purpose elastomers, such as natural rubber, or styrene-butadiene rubber, since most of the developments reported in the fourth generation concern rubbers for specific applications, such as polyurethanes or silicones. However, and despite great efforts, self-healing rubbers, and self-healing materials in general, continue to present serious limitations that should be resolved in the near future.

One of the main limitations is the absence of a unified protocol that permits quantifying the healing capability and, thus, establishing comparisons between systems or families of materials. This limitation becomes more important when trying to compare 


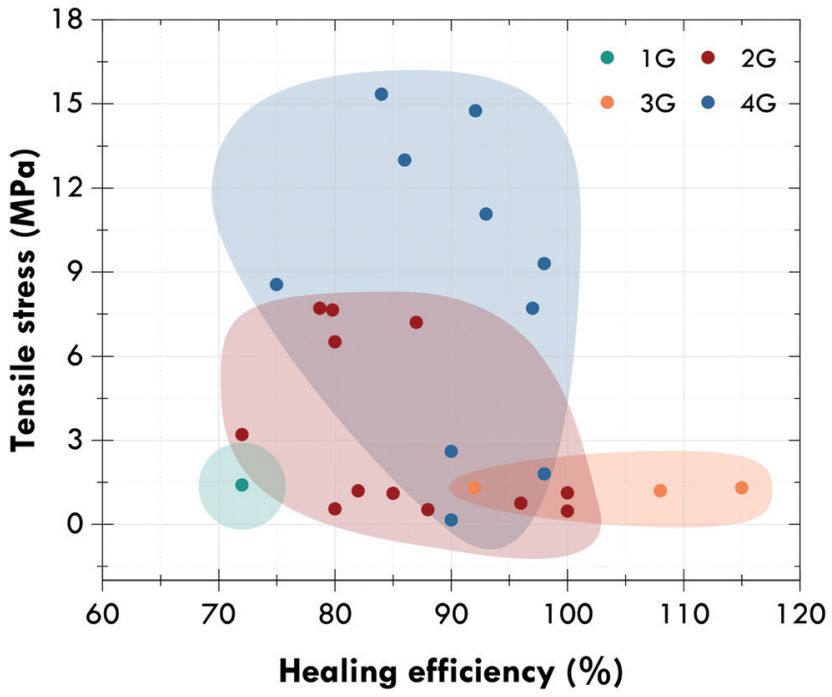

Fig. 12 Ashby diagram of the four generations of self-healing elastomers.

generations, where measuring protocols are different. As an illustrative example, healing within the first generation (encapsulated extrinsic systems) is usually measured through fracture toughness $\left(K_{\mathrm{IC}}\right)$ tests, while in the second and fourth (essentially intrinsic systems), healing is predominantly measured by tensile tests. This difference in criteria, even within the same generation, makes it difficult to establish fair comparisons between materials. The second limitation is related to the type of damage; it is urgent to think about their real scalability. Evaluating the tensile behavior and fracture toughness or monitoring superficial cracks is insufficient to ensure the behavior in service of self-healing materials. This scalability also refers to the evaluation of self-healing not only from the point of view of structural properties, but also regarding key limitations and properties defined for specific applications. Fatigue resistance, thermal and electrical conductivity, aging and the dichotomy itself between the dynamic nature of the reversible bonds and the stability of the materials (for example, chemical and thermal), among others, should be considered as soon as possible, to make the practical applicability of these strategies a reality.

Finally, according to World Bank estimates, global waste will grow $70 \%$ by 2050 , increasing from 2.1 billion tons registered in 2016 to 3.4 billion tons. ${ }^{225}$ More than $12 \%$ of this waste will be of polymeric origin. This review has presented the latest advances related to an effective alternative for reducing waste, extending the lifetime, and contributing to the evolution of smart materials. We hope that it will serve as an inspiration to researchers around the world to join efforts and make progress towards a more sustainable society. The world needs it.

\section{List of abbreviations}

$\begin{array}{ll}\text { AAm } & \text { Acrylic amide } \\ \text { AMPS } & \text { Aminopropyl methyl phenyl polysiloxanes } \\ \text { APB } & \text { 3-Aminophenylboronic acid } \\ \text { BIIR } & \text { Brominated butyl rubber } \\ \text { BNR } & \text { Brominated natural rubber }\end{array}$

\section{bPEI \\ BR \\ $\mathrm{ChCl}$ \\ CR \\ DA \\ DCPD \\ DTDA \\ DTSA \\ EMAA \\ ENR \\ EPDM \\ ES \\ FTIR \\ hbPAM \\ HPLC \\ HTPB \\ IPDI \\ IR}

IIR

MA

MPU

NBR

NR

PAA

PAN

PBMM

PBS

PCL

P-Cur

PDMS

PEO

PMMA

POU

PPC

PPG

PS

PU

PUE

PUU

PVA

PVAC

SBR

SBS

SEM

SM

TFP

TPU

UPy

UV

WBPU

WSP

XSBR
Branched poly(ethyleneimine)

Butadiene rubber

Choline chloride

Chloroprene rubber

Diels-Alder

Dicyclopentadiene

4,4-Dithiodianiline

2,2-Dithiodibenzoic acid

Ethylene-methacrylic acid

Epoxidized natural rubber

Ethylene propylene diene rubber

Electrospinning

Fourier-transform infrared spectroscopy

Hyperbranched polyazomethine

High-performance liquid chromatography

Hydroxy-terminated polybutadiene

Isophorone diisocyanate

Poly(isoprene)

Butyl rubber

Maleic acid

Maleimide end-capped polyurethane elastomer

Nitrile rubber

Natural rubber

Poly(acrylic acid)

Polyacrylonitrile

Poly(butyl methanol methacrylate)

Poly(butylene succinate)

$\varepsilon$-Caprolactone

Curcumin polymer block

Poly(dimethylsiloxane)

Poly(ethylene oxide)

Poly(methyl methacrylate)

Poly(oxime-urethane)

Poly(propylene carbonate)

Poly(propylene glycol)-based thiol

Polystyrene

Polyurethane

Polyurea elastomer

Poly(urea-urethane)

Poly(vinyl alcohol)

Poly(vinyl acetate)

Styrene butadiene rubber

Styrene butadiene styrene rubber

Scanning electron microscopy

Shape memory

Tri(2-furyl) phosphoramide

Thermoplastic polyurethane

2-Ureido-4[1 $\mathrm{H}]$-pyrimidione

Ultraviolet

Waterborne polyurethane

Water-soluble supramolecular polymer

Carboxylated styrene butadiene rubber

\section{Conflicts of interest}

There are no conflicts to declare. 


\section{Acknowledgements}

The authors acknowledge the Ministry of Science and Innovation of Spain for a research contracts (MAT2015-73392-JIN and PID2019-107501RB-I00) and M. Hernández Santana for a Ramón y Cajal contract (RYC-2017-22837).

\section{References}

1 J. Korhonen, A. Honkasalo and J. Seppälä, Ecol. Econ., 2018, 143, 37-46.

2 M. A. Reuter, A. van Schaik, J. Gutzmer, N. Bartie and A. Abadías-Llamas, Annu. Rev. Mater. Res., 2019, 49, 253-274.

3 S. Ramarad, M. Khalid, C. T. Ratnam, A. L. Chuah and W. Rashmi, Prog. Mater. Sci., 2015, 72, 100-140.

4 K. Aoudia, S. Azem, N. Ait Hocine, M. Gratton, V. Pettarin and S. Seghar, Waste Manage., 2017, 60, 471-481.

5 B. J. Blaiszik, S. L. B. Kramer, S. C. Olugebefola, J. S. Moore, N. R. Sottos and S. R. White, Annu. Rev. Mater. Res., 2010, 40, 179-211.

6 D. G. Bekas, K. Tsirka, D. Baltzis and A. S. Paipetis, Composites, Part B, 2016, 87, 92-119.

7 J. Dahlke, S. Zechel, M. D. Hager and U. S. Schubert, Adv. Mater. Interfaces, 2018, 5, 1800051.

8 L. Imbernon and S. Norvez, Eur. Polym. J., 2016, 82, 347-376. 9 M. Hernández Santana, M. den Brabander, S. García and S. van der Zwaag, Polym. Rev., 2018, 58, 585-609.

10 Z. Wang, X. Lu, S. Sun, C. Yu and H. Xia, J. Mater. Chem. B, 2019, 7, 4876-4926.

11 R. V. S. P. Sanka, B. Krishnakumar, Y. Leterrier, S. Pandey, S. Rana and V. Michaud, Front. Mater., 2019, 6.

12 S. Van der Zwaag and E. Brinkman, in Self Healing Materials: Pioneering Research in the Netherlands, ed. S. Van der Zwaag and E. Brinkman, IOS Press, The Netherlands, 2015.

13 S. R. White, N. R. Sottos, P. H. Geubelle, J. S. Moore, M. R. Kessler, S. R. Sriram, E. N. Brown and S. Viswanathan, Nature, 2001, 409, 794-797.

14 B. J. Blaiszik, N. R. Sottos and S. R. White, Compos. Sci. Technol., 2008, 68, 978-986.

15 X.-F. Wu, A. Rahman, Z. Zhou, D. D. Pelot, S. Sinha-Ray, B. Chen, S. Payne and A. L. Yarin, J. Appl. Polym. Sci., 2013, 129, 1383-1393.

16 X. Y. Jia, J. F. Mei, J. C. Lai, C. H. Li and X. Z. You, Macromol. Rapid Commun., 2016, 37, 952-956.

17 L. Feng, Z. Yu, Y. Bian, J. Lu, X. Shi and C. Chai, Polymer, 2017, 124, 48-59.

18 C. Xu, L. Cao, B. Lin, X. Liang and Y. Chen, ACS Appl. Mater. Interfaces, 2016, 8, 17728-17737.

19 D. Wang, J. Guo, H. Zhang, B. Cheng, H. Shen, N. Zhao and J. Xu, J. Mater. Chem. A, 2015, 3, 12864-12872.

20 J. Araujo-Morera, M. Hernández Santana, R. Verdejo and M. A. López-Manchado, Polymers, 2019, 11, 2122.

21 B. Willocq, J. Odent, P. Dubois and J.-M. Raquez, $R S C A d v$., 2020, 10, 13766-13782.

22 M. W. Lee, S. An, S. S. Yoon and A. L. Yarin, Adv. Colloid Interface Sci., 2018, 252, 21-37.
23 Y. M. Malinskii, V. V. Prokopenko, N. A. Ivanova and V. A. Kargin, Polym. Mech., 1970, 6, 240-244.

24 Y. M. Malinskii, V. V. Prokopenko, N. A. Ivanova and V. S. Kargin, Polym. Mech., 1970, 6, 382-384.

25 Y. M. Malinskii, V. V. Prokopenko and V. A. Kargin, Polym. Mech., 1970, 6, 969-972.

26 K. Jud, H. H. Kausch and J. G. Williams, J. Mater. Sci., 1981, 16, 204-210.

27 R. P. Wool and K. M. O'Connor, J. Appl. Phys., 1981, 52, 5953-5963.

28 R. P. Wool and K. M. O’Connor, J. Polym. Sci., Polym. Lett. Ed., 1982, 20, 7-16.

29 L. Zhai, A. Narkar and K. Ahn, Nano Today, 2020, 30, 100826, DOI: 10.1016/j.nantod.2019.100826.

30 M. D. Ellul and A. N. Gent, J. Polym. Sci., Polym. Phys. Ed., 1984, 22, 1953-1968.

31 C. Dry, Int. J. Mod. Phys. B, 1992, 06, 2763-2771.

32 C. M. Dry and N. R. Sottos, Proc. SPIE 1916, Smart Structures and Materials 1993: Smart Materials, 1993, 1916.

33 M. W. Keller, S. R. White and N. R. Sottos, Adv. Funct. Mater., 2007, 17, 2399-2404.

34 D. Y. Zhu, M. Z. Rong and M. Q. Zhang, Prog. Polym. Sci., 2015, 49-50, 175-220.

35 X. Chen, M. A. Dam, K. Ono, A. Mal, H. Shen, S. R. Nutt, K. Sheran and F. Wudl, Science, 2002, 295, 1698-1702.

36 P. Cordier, F. Tournilhac, C. Soulie-Ziakovic and L. Leibler, Nature, 2008, 451, 977-980.

37 K. S. Toohey, N. R. Sottos, J. A. Lewis, J. S. Moore and S. R. White, Nat. Mater., 2007, 6, 581-585.

38 M. W. Lee, S. An, C. Lee, M. Liou, A. L. Yarin and S. S. Yoon, J. Mater. Chem. A, 2014, 2.

39 S. An, M. Liou, K. Y. Song, H. S. Jo, M. W. Lee, S. S. Al-Deyab, A. L. Yarin and S. S. Yoon, Nanoscale, 2015, 7, 17778-17785.

40 M. W. Lee, S. An, H. S. Jo, S. S. Yoon and A. L. Yarin, ACS Appl. Mater. Interfaces, 2015, 7, 19546-19554.

41 M. W. Lee, S. An, H. S. Jo, S. S. Yoon and A. L. Yarin, ACS Appl. Mater. Interfaces, 2015, 7, 19555-19561.

42 U. S. Chung, J. H. Min, P.-C. Lee and W.-G. Koh, Colloids Surf., A, 2017, 518, 173-180.

43 M. W. Lee, S. An, Y.-I. Kim, S. S. Yoon and A. L. Yarin, Chem. Eng. J., 2018, 334, 1093-1100.

44 Y. Zhu, Q. Shen, L. Wei, X. Fu, C. Huang, Y. Zhu, L. Zhao, G. Huang and J. Wu, ACS Appl. Mater. Interfaces, 2019, 11, 29373-29381.

45 Q. Guo, X. Zhang, F. Zhao, Q. Song, G. Su, Y. Tan, Q. Tao, T. Zhou, Y. Yu, Z. Zhou and C. Lu, ACS Nano, 2020, 14(3), 2788-2797, DOI: 10.1021/acsnano.9b09802.

46 R. Li, T. Fan, G. Chen, K. Zhang, B. Su, J. Tian and M. He, Chem. Mater., 2020, 32(2), 874-881, DOI: 10.1021/acs. chemmater.9b04592.

47 Z. He, S. Jiang, N. An, X. Li, Q. Li, J. Wang, Y. Zhao and M. Kang, J. Mater. Sci., 2019, 54, 8262-8275.

48 Z. Yin, J. Guo, J. Qiao and X. Chen, Colloid Polym. Sci., 2020, 298, 67-77, DOI: 10.1007/s00396-019-04587-2.

49 Y. Cao, H. Wu, S. I. Allec, B. M. Wong, D. S. Nguyen and C. Wang, Adv. Mater., 2018, 30, 1804602. 
50 J. Nie, W. Mou, J. Ding and Y. Chen, Composites, Part B, 2019, 172, 152-160.

51 L. Cao, D. Yuan, C. Xu and Y. Chen, Nanoscale, 2017, 9, 15696-15706.

52 S. Utrera-Barrios, M. Hernández Santana, R. Verdejo and M. A. López-Manchado, ACS Omega, 2020, 5, 1902-1910.

53 C. Xu, J. Nie, W. Wu, Z. Zheng and Y. Chen, ACS Sustainable Chem. Eng., 2019, 7, 15778-15789.

54 D.-D. Zhang, Y.-B. Ruan, B.-Q. Zhang, X. Qiao, G. Deng, Y. Chen and C.-Y. Liu, Polymer, 2017, 120, 189-196.

55 P.-F. Cao, B. Li, T. Hong, J. Townsend, Z. Qiang, K. Xing, K. D. Vogiatzis, Y. Wang, J. W. Mays, A. P. Sokolov and T. Saito, Adv. Funct. Mater., 2018, 28.

56 J. Kang, D. Son, G. N. Wang, Y. Liu, J. Lopez, Y. Kim, J. Y. Oh, T. Katsumata, J. Mun, Y. Lee, L. Jin, J. B. Tok and Z. Bao, Adv. Mater., 2018, 30, e1706846.

57 E. Ogliani, L. Yu, I. Javakhishvili and A. L. Skov, $R S C A d v$, 2018, 8, 8285-8291.

58 L. Chen, H. Peng, Y. Wei, X. Wang, Y. Jin, H. Liu and Y. Jiang, Macromol. Chem. Phys., 2019, 220.

59 Y. Liu, K. Zhang, J. Sun, J. Yuan, Z. Yang, C. Gao and Y. Wu, Ind. Eng. Chem. Res., 2019, 58(47), 21452-21458, DOI: 10.1021/acs.iecr.9b03953.

60 R. Du, Z. Xu, C. Zhu, Y. Jiang, H. Yan, H. C. Wu, O. Vardoulis, Y. Cai, X. Zhu, Z. Bao, Q. Zhang and X. Jia, Adv. Funct. Mater., 2019, 30.

61 L. Zhang, D. Wang, L. Xu, X. Zhang, A. Zhang and Y. Xu, J. Mater. Chem. C, 2020, 8, 2043-2053, DOI: 10.1039/ c9tc05612b.

62 X. Qi, J. Zhang, L. Zhang and D. Yue, J. Mater. Sci., 2020, 55, 4940-4951, DOI: 10.1007/s10853-019-04272-3.

63 L. Liu, L. Zhu and L. Zhang, Macromol. Chem. Phys., 2018, 219.

64 A. M. Grande, S. J. Garcia and S. van der Zwaag, Polymer, 2015, 56, 435-442.

65 L. Liu, W. Zhang, N. Ning and L. Zhang, Chem. Eng. J., 2019, 375.

66 F. Sordo, S.-J. Mougnier, N. Loureiro, F. Tournilhac and V. Michaud, Macromolecules, 2015, 48, 4394-4402.

67 B. Wu, Z. Liu, Y. Lei, Y. Wang, Q. Liu, A. Yuan, Y. Zhao, X. Zhang and J. Lei, Polymer, 2020, 186, 122003, DOI: 10.1016/j.polymer.2019.122003.

68 X. Yan, Z. Liu, Q. Zhang, J. Lopez, H. Wang, H. C. Wu, S. Niu, H. Yan, S. Wang, T. Lei, J. Li, D. Qi, P. Huang, J. Huang, Y. Zhang, Y. Wang, G. Li, J. B. Tok, X. Chen and Z. Bao, J. Am. Chem. Soc., 2018, 140, 5280-5289.

69 F. Fan and J. Szpunar, J. Appl. Polym. Sci., 2015, 132, 42135.

70 M. Li, B. Zhou, Q. Lyu, L. Jia, H. Tan, Z. Xie, B. Xiong, Z. Xue, L. Zhang and J. Zhu, Mater. Chem. Front., 2019, 3, 2707-2715.

71 J. Wu, L. H. Cai and D. A. Weitz, Adv. Mater., 2017, 29, 1702616.

72 R. Li, T. Fan, G. Chen, H. Xie, B. Su and M. Hui He, Chem. Eng. J., 2020, 393, 124685, DOI: 10.1016/j.cej.2020.124685.

73 C. Xu, L. Cao, X. Huang, Y. Chen, B. Lin and L. Fu, ACS Appl. Mater. Interfaces, 2017, 9, 29363-29373.
74 S. R. Khimi, S. N. Syamsinar and T. N. L. Najwa, Mater. Today: Proc., 2019, 17, 1064-1071.

75 N. L. N. Thajudin, N. S. Sardi, M. H. Zainol and R. K. Shuib, J. Rubber Res., 2019, 22, 203-211, DOI: 10.1007/s42464-01900025-8.

76 Y. Liu, Z. Li, R. Liu, Z. Liang, J. Yang, R. Zhang, Z. Zhou and Y. Nie, Ind. Eng. Chem. Res., 2019, 58, 14848-14858.

77 X. Yang, J. Liu, D. Fan, J. Cao, X. Huang, Z. Zheng and X. Zhang, Chem. Eng. J., 2020, 389, 124448, DOI: 10.1016/ j.cej.2020.124448.

78 A. Das, A. Sallat, F. Bohme, M. Suckow, D. Basu, S. Wiessner, K. W. Stockelhuber, B. Voit and G. Heinrich, ACS Appl. Mater. Interfaces, 2015, 7, 20623-20630.

79 H. H. Le, F. Böhme, A. Sallat, S. Wießner, M. auf der Landwehr, U. Reuter, K.-W. Stöckelhuber, G. Heinrich, H.-J. Radusch and A. Das, Macromol. Mater. Eng., 2017, 302, 1600385.

80 A. Das, A. Sallat, F. Bohme, E. Sarlin, J. Vuorinen, N. Vennemann, G. Heinrich and K. W. Stockelhuber, Polymers, 2018, 10, 94.

81 Z.-F. Zhang, K. Yang, S.-G. Zhao and L.-N. Guo, Chin. J. Polym. Sci., 2019, 37, 700-707.

82 F. B. Madsen, L. Yu and A. L. Skov, ACS Macro Lett., 2016, 5, 1196-1200.

83 Z. Liu, P. Hong, Z. Huang, T. Zhang, R. Xu, L. Chen, H. Xiang and X. Liu, Chem. Eng. J., 2020, 387.

84 Y. Peng, L. Zhao, C. Yang, Y. Yang, C. Song, Q. Wu, G. Huang and J. Wu, J. Mater. Chem. A, 2018, 6, 19066-19074.

85 H. H. Le, S. Hait, A. Das, S. Wiessner, K. W. Stoeckelhuber, F. Boehme, R. Uta, K. Naskar, G. Heinrich and H. J. Radusch, eXPRESS Polym. Lett., 2017, 11, 230-242.

86 W. Wu, Y. Zhou, J. Li and C. Wan, J. Appl. Polym. Sci., 2020, 48666, DOI: 10.1002/app.48666.

87 M. Suckow, A. Mordvinkin, M. Roy, N. K. Singha, G. Heinrich, B. Voit, K. Saalwächter and F. Böhme, Macromolecules, 2017, 51, 468-479.

88 A. Sallat, A. Das, J. Schaber, U. Scheler, E. S. Bhagavatheswaran, K. W. Stöckelhuber, G. Heinrich, B. Voit and F. Böhme, RSC Adv., 2018, 8, 26793-26803.

89 Z. F. Zhang, X. T. Liu, K. Yang and S. G. Zhao, Macromol. Res., 2019, 27, 803-810.

90 X. Y. Jia, J. F. Mei, J. C. Lai, C. H. Li and X. Z. You, Chem. Commun., 2015, 51, 8928-8930.

91 C. H. Li, C. Wang, C. Keplinger, J. L. Zuo, L. Jin, Y. Sun, P. Zheng, Y. Cao, F. Lissel, C. Linder, X. Z. You and Z. Bao, Nat. Chem., 2016, 8, 618-624.

92 Y. L. Rao, A. Chortos, R. Pfattner, F. Lissel, Y. C. Chiu, V. Feig, J. Xu, T. Kurosawa, X. Gu, C. Wang, M. He, J. W. Chung and Z. Bao, J. Am. Chem. Soc., 2016, 138, 6020-6027.

93 Y. Lei, Q. Huang, S. Shan, Y. Lin and A. Zhang, New J. Chem., 2019, 43, 17441-17445, DOI: 10.1039/c9nj03909k.

94 I. Oh, S. I. Jeon, I. J. Chung and C.-H. Ahn, Macromol. Res., 2019, 27, 435-443.

95 Y. Lei, W. Huang, Q. Huang and A. Zhang, New J. Chem., 2019, 43, 261-268. 
96 H. Tan, Q. Lyu, Z. Xie, M. Li, K. Wang, K. Wang, B. Xiong, L. Zhang and J. Zhu, Adv. Mater., 2019, 31, e1805496.

97 Z. Li, Y. Shan, X. Wang, H. Li, K. Yang and Y. Cui, Chem. Eng. J., 2020, 394.

98 B. Peng, H. Li, Y. Li, Z. Lv, M. Wu and C. Zhao, Chem. Eng. J., 2020, 395.

99 Z. Wang, C. Xie, C. Yu, G. Fei, Z. Wang and H. Xia, Macromol. Rapid Commun., 2018, 39, e1700678.

100 D. Yu, X. Zhao, C. Zhou, C. Zhang and S. Zhao, Macromol. Chem. Phys., 2017, 218.

101 H. Wang, W. Liu, Z. Tu, J. Huang and X. Qiu, Ind. Eng. Chem. Res., 2019, 58, 23114-23123.

102 S. Nomimura, M. Osaki, J. Park, R. Ikura, Y. Takashima, H. Yamaguchi and A. Harada, Macromolecules, 2019, 52, 2659-2668.

103 J. Huang, L. Cao, D. Yuan and Y. Chen, ACS Appl. Mater. Interfaces, 2018, 10, 40996-41002.

104 P. Tanasi, M. Hernández Santana, J. Carretero-González, R. Verdejo and M. A. López-Manchado, Polymer, 2019, 175, 15-24.

105 X. Kuang, G. Liu, X. Dong and D. Wang, Macromol. Mater. Eng., 2016, 301, 535-541.

106 Z. Jia, S. Zhu, Y. Chen, W. Zhang, B. Zhong and D. Jia, Composites, Part A, 2020, 129, 105709.

107 J. Zhao, R. Xu, G. Luo, J. Wu and H. Xia, J. Mater. Chem. B, 2016, 4, 982-989.

108 A. Nasresfahani and P. M. Zelisko, Polym. Chem., 2017, 8, 2942-2952.

109 J. Wang, C. Lv, Z. Li and J. Zheng, Macromol. Mater. Eng., 2018, 303, 1800089.

110 Q. Yan, L. Zhao, Q. Cheng, T. Zhang, B. Jiang, Y. Song and Y. Huang, Ind. Eng. Chem. Res., 2019, 58(47), 21504-21512, DOI: 10.1021/acs.iecr.9b04355.

111 L. Zhao, X. Shi, Y. Yin, B. Jiang and Y. Huang, Compos. Sci. Technol., 2020, 186, 107919, DOI: 10.1016/j.compscitech. 2019.107919.

112 Y. Fang, X. Du, S. Yang, H. Wang, X. Cheng and Z. Du, Polym. Chem., 2019, 10, 4142-4153.

113 L. Feng, Y. Bian, C. Chai and X. Qiang, J. Polym. Environ., 2020, 28, 647-656, DOI: 10.1007/s10924-019-01633-6.

114 S. Yang, S. Wang, X. Du, X. Cheng, H. Wang and Z. Du, Polym. Chem., 2020, 11, 1161-1170, DOI: 10.1039/c9py01531k.

115 T. T. Truong, S. H. Thai, H. T. Nguyen, D. T. T. Phung, L. T. Nguyen, H. Q. Pham and L.-T. T. Nguyen, Chem. Mater., 2019, 31, 2347-2357.

116 Y. Fang, J. Li, X. Du, Z. Du, X. Cheng and H. Wang, Polymer, 2018, 158, 166-175.

117 G. Fu, L. Yuan, G. Liang and A. Gu, J. Mater. Chem. A, 2016, 4, 4232-4241.

118 T. Wang, W.-C. Yu, C.-G. Zhou, W.-J. Sun, Y.-P. Zhang, L.-C. Jia, J.-F. Gao, K. Dai, D.-X. Yan and Z.-M. Li, Composites, Part B, 2020, 193.

119 S. Schäfer and G. Kickelbick, Polymer, 2015, 69, 357-368.

120 Z. Gou, Y. Zuo and S. Feng, RSC Adv., 2016, 6, 73140-73147.

121 J. Bai, H. Li, Z. Shi, M. Tian and J. Yin, $R S C A d v .$, 2015, 5, 45376-45383.
122 J. Bai, Q. He, Z. Shi, M. Tian, H. Xu, X. Ma and J. Yin, Polymer, 2017, 116, 268-277.

123 J. Bai and Z. Shi, ACS Appl. Mater. Interfaces, 2017, 9, 27213-27222.

124 G. Li, P. Xiao, S. Hou and Y. Huang, Carbon, 2019, 147, 398-407.

125 J. Brancart, R. Verhelle, J. Mangialetto and G. V. Assche, Coatings, 2018, 9.

126 S. Terryn, G. Mathijssen, J. Brancart, D. Lefeber, G. V. Assche and B. Vanderborght, Bioinspiration Biomimetics, 2015, 10, 046007.

127 S. Terryn, J. Brancart, D. Lefeber, G. Van Assche and B. Vanderborght, Sci. Robot., 2017, 2, eaan4268.

128 S. Terryn, J. Brancart, D. Lefeber, G. Van Assche and B. Vanderborght, IEEE Robot. Autom. Lett., 2018, 3, 16-21.

129 E. Roels, S. Terryn, J. Brancart, R. Verhelle, G. Van Assche and B. Vanderborght, Soft Robot., 2020, DOI: 10.1089/ soro.2019.0081.

130 S. Terryn, E. Roels, J. Brancart, G. V. Assche and B. Vanderborght, Actuators, 2020, 9.

131 M. Hernández, A. M. Grande, W. Dierkes, J. Bijleveld, S. van der Zwaag and S. J. García, ACS Sustainable Chem. Eng., 2016, 4, 5776-5784.

132 M. Hernández, A. M. Grande, S. van der Zwaag and S. J. Garcia, ACS Appl. Mater. Interfaces, 2016, 8, 10647-10656.

133 M. Hernández, M. M. Bernal, A. M. Grande, N. Zhong, S. van der Zwaag and S. J. García, Smart Mater. Struct., 2017, 26, 085010.

134 M. Hernández Santana, M. Huete, P. Lameda, J. Araujo, R. Verdejo and M. A. López-Manchado, Eur. Polym. J., 2018, 106, 273-283.

135 H. P. Xiang, H. J. Qian, Z. Y. Lu, M. Z. Rong and M. Q. Zhang, Green Chem., 2015, 17, 4315-4325.

136 H. Xiang, J. Yin, G. Lin, X. Liu, M. Rong and M. Zhang, Chem. Eng. J., 2019, 358, 878-890.

137 H. P. Xiang, M. Z. Rong and M. Q. Zhang, ACS Sustainable Chem. Eng., 2016, 4, 2715-2724.

138 H. P. Xiang, M. Z. Rong and M. Q. Zhang, Polymer, 2017, 108, 339-347.

139 L. Zhao, Y. Yin, B. Jiang, Z. Guo, C. Qu and Y. Huang, J. Colloid Interface Sci., 2020, 573, 105-114.

140 Y. Xu and D. Chen, Macromol. Chem. Phys., 2016, 217, 1191-1196.

141 L. Zhang, T. Qiu, X. Sun, L. Guo, L. He, J. Ye and X. Li, Polymers, 2020, 12.

142 Y. Chen, Z. Tang, X. Zhang, Y. Liu, S. Wu and B. Guo, ACS Appl. Mater. Interfaces, 2018, 10, 24224-24231.

143 J. Cao, D. Han, H. Lu, P. Zhang and S. Feng, New J. Chem., 2018, 42, 18517-18520.

144 C. Zhang, Z. Yang, N. T. Duong, X. Li, Y. Nishiyama, Q. Wu, R. Zhang and P. Sun, Macromolecules, 2019, 52, 5014-5025.

145 J. J. Cash, T. Kubo, A. P. Bapat and B. S. Sumerlin, Macromolecules, 2015, 48, 2098-2106.

146 J. Sun, X. Pu, M. Liu, A. Yu, C. Du, J. Zhai, W. Hu and Z. L. Wang, ACS Nano, 2018, 12, 6147-6155.

147 P. Wang, L. Yang, B. Dai, Z. Yang, S. Guo, G. Gao, L. Xu, M. Sun, K. Yao and J. Zhu, Eur. Polym. J., 2020, 123, 109382. 
148 X. Lei, Y. Huang, S. Liang, X. Zhao and L. Liu, Mater. Lett., 2020, 268, 127598, DOI: 10.1016/j.matlet.2020.127598.

149 C. Xu, R. Cui, L. Fu and B. Lin, Compos. Sci. Technol., 2018, 167, 421-430.

150 L. Cao, J. Fan, J. Huang and Y. Chen, J. Mater. Chem. A, 2019, 7, 4922-4933.

151 Z. Feng, J. Hu, H. Zuo, N. Ning, L. Zhang, B. Yu and M. Tian, ACS Appl. Mater. Interfaces, 2019, 11, 1469-1479.

152 X. Yang, Y. Guo, X. Luo, N. Zheng, T. Ma, J. Tan, C. Li, Q. Zhang and J. Gu, Compos. Sci. Technol., 2018, 164, 59-64.

153 K.-H. Wu, L.-F. Feng, X.-P. Gu, C.-L. Zhang and S. Shen, Ind. Eng. Chem. Res., 2018, 57, 946-953.

154 D. Fu, W. Pu, Z. Wang, X. Lu, S. Sun, C. Yu and H. Xia, J. Mater. Chem. A, 2018, 6, 18154-18164.

155 B. Zhao, H. Ding, S. Xu and S. Zheng, ACS Appl. Polym. Mater., 2019, 1(11), 3174-3184, DOI: 10.1021/acsapm.9b00830.

156 M. W. Lee, S. Sett, S. An, S. S. Yoon and A. L. Yarin, ACS Appl. Mater. Interfaces, 2017, 9, 27223-27231.

157 M. W. Lee, S. S. Yoon and A. L. Yarin, ACS Appl. Mater. Interfaces, 2017, 9, 17449-17455.

158 S. Burattini, B. W. Greenland, D. H. Merino, W. Weng, J. Seppala, H. M. Colquhoun, W. Hayes, M. E. Mackay, I. W. Hamley and S. J. Rowan, J. Am. Chem. Soc., 2010, 132, 12051-12058.

159 Z. Jiang, A. Bhaskaran, H. M. Aitken, I. C. G. Shackleford and L. A. Connal, Macromol. Rapid Commun., 2019, 40, 1900038.

160 L. Li and J. K. Kim, Rubber Chem. Technol., 2014, 87, 459-470.

161 J. Liu, S. Wang, Z. Tang, J. Huang, B. Guo and G. Huang, Macromolecules, 2016, 49, 8593-8604.

162 C. Li, Y. Wang, Z. Yuan and L. Ye, Appl. Surf. Sci., 2019, 484, 616-627.

163 Y. Liu, Z. Tang, S. Wu and B. Guo, ACS Macro Lett., 2019, 8, 193-199.

164 Y. Zuo, Y. Zhang, T. Yang, Z. Gou and W. Lin, New J. Chem., 2018, 42, 14281-14289.

165 C. Xu, J. Nie, W. Wu, L. Fu and B. Lin, Carbohydr. Polym., 2019, 205, 410-419.

166 M. A. Sattar, S. Gangadharan and A. Patnaik, ACS Omega, 2019, 4, 10939-10949.

167 H. Guo, X. Fang, L. Zhang and J. Sun, ACS Appl. Mater. Interfaces, 2019, 11, 33356-33363.

168 H. Sun, X. Liu, S. Liu, B. Yu, N. Ning, M. Tian and L. Zhang, Chem. Eng. J., 2020, 384, 123242.

169 G. Ye, Z. Song, T. Yu, Q. Tan, Y. Zhang, T. Chen, C. He, L. Jin and N. Liu, ACS Appl. Mater. Interfaces, 2020, 12(1), 1486-1494, DOI: 10.1021/acsami.9b17354.

170 S. Stein, A. Mordvinkin, B. Voit, H. Komber, K. Saalwächter and F. Böhme, Polym. Chem., 2020, 11, 1188-1197, DOI: 10.1039/c9py01630a.

171 X. Wang, D. Liang and B. Cheng, Compos. Sci. Technol., 2020, 193.

172 J. Liu, J. Liu, S. Wang, J. Huang, S. Wu, Z. Tang, B. Guo and L. Zhang, J. Mater. Chem. A, 2017, 5, 25660-25671.
173 Q. Zhang, S. Niu, L. Wang, J. Lopez, S. Chen, Y. Cai, R. Du, Y. Liu, J. C. Lai, L. Liu, C. H. Li, X. Yan, C. Liu, J. B. Tok, X. Jia and Z. Bao, Adv. Mater., 2018, e1801435, DOI: 10.1002/adma.201801435.

174 X. Wu, J. Wang, J. Huang and S. Yang, ACS Appl. Mater. Interfaces, 2019, 11, 7387-7396.

175 L. Zhang, Z. Liu, X. Wu, Q. Guan, S. Chen, L. Sun, Y. Guo, S. Wang, J. Song, E. M. Jeffries, C. He, F. L. Qing, X. Bao and Z. You, Adv. Mater., 2019, 31, 1901402.

176 X. Cui, Y. Song, J.-P. Wang, J.-K. Wang, Q. Zhou, T. Qi and G. L. Li, Polymer, 2019, 174, 143-149.

177 B. Yi, P. Liu, C. Hou, C. Cao, J. Zhang, H. Sun and X. Yao, ACS Appl. Mater. Interfaces, 2019, 11, 47382-47389.

178 S. Xu, D. Sheng, Y. Zhou, H. Wu, H. Xie, X. Tian, Y. Sun, X. Liu and Y. Yang, New J. Chem., 2020, 44, 7395-7400.

179 J. B. Hou, X. Q. Zhang, D. Wu, J. F. Feng, D. Ke, B. J. Li and S. Zhang, ACS Appl. Mater. Interfaces, 2019, 11, 12105-12113.

180 L. Xiao, J. Shi, K. Wu and M. Lu, React. Funct. Polym., 2020, 148, 104482, DOI: 10.1016/j.reactfunctpolym.2020.104482.

181 J. Chen, F. Li, Y. Luo, Y. Shi, X. Ma, M. Zhang, D. W. Boukhvalov and Z. Luo, J. Mater. Chem. A, 2019, 7, 15207-15214.

182 M. Tang, P. Zheng, K. Wang, Y. Qin, Y. Jiang, Y. Cheng, Z. Li and L. Wu, J. Mater. Chem. A, 2019, 7, 27278-27288.

183 C. Ellingford, A. M. Wemyss, R. Zhang, I. Prokes, T. Pickford, C. Bowen, V. A. Coveney and C. Wan, J. Mater. Chem. C, 2020, 8, 5426-5436.

184 J. F. Mei, X. Y. Jia, J. C. Lai, Y. Sun, C. H. Li, J. H. Wu, Y. Cao, X. Z. You and Z. Bao, Macromol. Rapid Commun., 2016, 37, 1667-1675.

185 J. Liu, C. Xiao, J. Tang, Y. Liu and J. Hua, Ind. Eng. Chem. Res., 2020, 59(28), 12755-12765, DOI: 10.1021/acs.iecr.0c01538.

186 C. Lv, K. Zhao and J. Zheng, Macromol. Rapid Commun., 2018, 39, 1700686.

187 S.-H. Lee, S.-R. Shin and D.-S. Lee, Mater. Des., 2019, 172, 107774.

188 X. Dai, Y. Du, Y. Wang, Y. Liu, N. Xu, Y. Li, D. Shan, B. B. Xu and J. Kong, ACS Appl. Polym. Mater., 2020, 2, 1065-1072.

189 A. Rekondo, R. Martin, A. Ruiz de Luzuriaga, G. Cabañero, H. J. Grande and I. Odriozola, Mater. Horiz., 2014, 1, 237-240.

190 W. M. Xu, M. Z. Rong and M. Q. Zhang, J. Mater. Chem. A, 2016, 4, 10683-10690.

191 Y. Yang, X. Lu and W. Wang, Mater. Des., 2017, 127, 30-36. 192 X. Jian, Y. Hu, W. Zhou and L. Xiao, Polym. Adv. Technol., 2018, 29, 463-469.

193 T. Li, Z. Xie, J. Xu, Y. Weng and B.-H. Guo, Eur. Polym. J., 2018, 107, 249-257.

194 B. Cheng, X. Lu, J. Zhou, R. Qin and Y. Yang, ACS Sustainable Chem. Eng., 2019, 7, 4443-4455.

$195 \mathrm{~J} . \mathrm{Hu}, \mathrm{R} . \mathrm{Mo}$, X. Jiang, X. Sheng and X. Zhang, Polymer, 2019, 183, 121912.

196 X. Li, R. Yu, Y. He, Y. Zhang, X. Yang, X. Zhao and W. Huang, ACS Macro Lett., 2019, 8, 1511-1516. 
197 W. Yao, X. Chen, Q. Tian, C. Luo, X. Zhang, H. Peng and W. Wu, Chem. Eng. J., 2020, 384, 123375, DOI: 10.1016/ j.cej.2019.123375.

198 M. Liu, J. Zhong, Z. Li, J. Rong, K. Yang, J. Zhou, L. Shen, F. Gao, X. Huang and H. He, Eur. Polym. J., 2020, 124, 109475.

199 H. Guo, Y. Han, W. Zhao, J. Yang and L. Zhang, Nat. Commun., 2020, 11, 2037.

200 J. Zhao, R. Xu, G. Luo, J. Wu and H. Xia, Polym. Chem., 2016, 7, 7278-7286.

201 S. Yang, S. Wang, X. Du, Z. Du, X. Cheng and H. Wang, Chem. Eng. J., 2020, 391, 123544, DOI: 10.1016/j.cej. 2019.123544.

202 Q. Guo, B. Huang, C. Lu, T. Zhou, G. Su, L. Jia and X. Zhang, Mater. Horiz., 2019, 6, 996-1004.

203 H. Yan, S. Dai, Y. Chen, J. Ding and N. Yuan, ChemistrySelect, 2019, 4, 10719-10725.

204 H. Zhang, D. Wang, N. Wu, C. Li, C. Zhu, N. Zhao and J. Xu, ACS Appl. Mater. Interfaces, 2020, 12(8), 9833-9841, DOI: 10.1021/acsami.9b22613.

205 Z. Yang, H. Li, L. Zhang, X. Lai and X. Zeng, J. Colloid Interface Sci., 2020, 570, 1-10.

206 W. Fan, Y. Jin, L. Shi, W. Du, R. Zhou, S. Lai, Y. Shen and Y. Li, ACS Appl. Mater. Interfaces, 2020, 12(5), 6383-6395, DOI: 10.1021/acsami.9b18985.

207 W. Fan, Y. Jin, L. Shi, W. Du and R. Zhou, Polymer, 2020, 190, 122199.

208 Y. Xu and D. Chen, Mater. Chem. Phys., 2017, 195, 40-48.

209 K. Chang, H. Jia and S.-Y. Gu, Eur. Polym. J., 2019, 112, 822-831.

210 Y.-m. Ha, Y.-O. Kim, S. Ahn, S.-k. Lee, J.-s. Lee, M. Park, J. W. Chung and Y. C. Jung, Eur. Polym. J., 2019, 118, 36-44.
211 Y. Peng, Y. Yang, Q. Wu, S. Wang, G. Huang and J. Wu, Polymer, 2018, 157, 172-179.

212 Y. Chen, Z. Tang, Y. Liu, S. Wu and B. Guo, Macromolecules, 2019, 52, 3805-3812.

213 J. Pignanelli, B. Billet, M. Straeten, M. Prado, K. Schlingman, M. J. Ahamed and S. Rondeau-Gagne, Soft Matter, 2019, 15, 7654-7662.

214 C. Lin, D. Sheng, X. Liu, S. Xu, F. Ji, L. Dong, Y. Zhou and Y. Yang, J. Polym. Sci., Part A: Polym. Chem., 2019, 57, 2228-2234.

215 Y.-H. Li, W.-J. Guo, W.-J. Li, X. Liu, H. Zhu, J.-P. Zhang, X.-J. Liu, L.-H. Wei and A.-L. Sun, Chem. Eng. J., 2020, 393, 124583, DOI: 10.1016/j.cej.2020.124583.

216 F. J. M. Hoeben, P. Jonkheijm, E. W. Meijer and A. P. H. J. Schenning, Chem. Rev., 2005, 105, 1491-1546.

217 Nature, 1950, 166(4230), 889, DOI: 10.1038/166889a0.

218 B. Zhang, Z. A. Digby, J. A. Flum, E. M. Foster, J. L. Sparks and D. Konkolewicz, Polym. Chem., 2015, 6, 7368-7372.

219 X. Kuang, K. Chen, C. K. Dunn, J. Wu, V. C. F. Li and H. J. Qi, ACS Appl. Mater. Interfaces, 2018, 10, 7381-7388.

220 C. Lv, J. Wang, Z. Li, K. Zhao and J. Zheng, Composites, Part B, 2019, 177, 107270.

221 W.-J. Lee and S.-H. Cha, Polymers, 2020, 12.

222 A. C. Balazs, Mater. Today, 2007, 10, 18-23.

223 T. Zhang, B. L. Mbanga, V. V. Yashin and A. C. Balazs, Mol. Syst. Des. Eng., 2017, 2, 490-499.

224 Z. Zhang, J. Liu, S. Li, K. Gao, V. Ganesan and L. Zhang, Macromolecules, 2019, 52, 4154-4168.

225 S. Kaza, L. Yao, P. Bhada-Tata and F. Van Woerden, What a waste 2.0: a global snapshot of solid waste management to 2050, The World Bank, 2018. 